\title{
LA-UR-19-29633
}

Approved for public release; distribution is unlimited.

Title: $\quad$ Eastern North Atlantic (ENA) Aerosol Supplementary Site (S1) Data Analysis Report

Author(s): $\quad$ Aiken, Allison C.; Gallo, Francesca; Uin, Janek; Springston, Stephen; Wang, Jian; Zheng, Guangjie; Kuang, Chongai; McComiskey, Allison; Wood, Rob; Flynn, Connor; Theisen, Adam; Azevedo, Eduardo

Intended for: Report

Issued: 
Disclaimer:

Los Alamos National Laboratory, an affirmative action/equal opportunity employer, is operated by Triad National Security, LLC for the National Nuclear Security Administration of U.S. Department of Energy under contract 89233218CNA000001. By approving this article, the publisher recognizes that the U.S. Government retains nonexclusive, royalty-free license to publish or reproduce the published form of this contribution, or to allow others to do so, for U.S. Government purposes. Los Alamos National Laboratory requests that the publisher identify this article as work performed under the auspices of the U.S. Department of Energy. Los Alamos National Laboratory strongly supports academic freedom and a researcher's right to publish; as an institution, however, the Laboratory does not endorse the viewpoint of a publication or guarantee its technical correctness. 


\section{Eastern North Atlantic (ENA) Aerosol Supplementary Site (S1) Data Analysis Report}

$\begin{array}{ll}\text { AC Aiken } & \text { F Gallo } \\ \text { J Uin } & \text { SR Springston } \\ \text { J Wang } & \text { G Zheng } \\ \text { C Kuang } & \text { A McComiskey } \\ \text { R Wood } & \text { C Flynn } \\ \text { A Theisen } & \text { E Azevedo } \\ \text { P Ortega } & \text { H Powers }\end{array}$

September 2019 


\section{DISCLAIMER}

This report was prepared as an account of work sponsored by the U.S. Government. Neither the United States nor any agency thereof, nor any of their employees, makes any warranty, express or implied, or assumes any legal liability or responsibility for the accuracy, completeness, or usefulness of any information, apparatus, product, or process disclosed, or represents that its use would not infringe privately owned rights. Reference herein to any specific commercial product, process, or service by trade name, trademark, manufacturer, or otherwise, does not necessarily constitute or imply its endorsement, recommendation, or favoring by the U.S. Government or any agency thereof. The views and opinions of authors expressed herein do not necessarily state or reflect those of the U.S. Government or any agency thereof. 


\section{Eastern North Atlantic (ENA) Aerosol Supplementary Site (S1) Data Analysis Report}

AC Aiken, Los Alamos National Laboratory (LANL)

Principal Investigator

F Gallo, LANL

J Uin, Brookhaven National Laboratory (BNL)

SR Springston, BNL

J Wang, Washington University, St. Louis (WUSL)

G Zheng, WUSL

C Kuang, BNL

A McComiskey, BNL

R Wood, University of Washington

C Flynn, University of Oklahoma

A Theisen, Argonne National Laboratory

E Azevedo, University of Azores

P Ortega, LANL

H Powers, LANL

Co-Investigators

September 2019

Work supported by the U.S. Department of Energy, Office of Science, Office of Biological and Environmental Research 


\section{Executive Summary}

We present strategies to identify time periods when local aerosol sources impact the data collected at the U.S. Department of Energy (DOE) Atmospheric Radiation Measurement (ARM) user facility in the Eastern North Atlantic (ENA). Data from the aerosol observing system (AOS) at the Central Facility and a temporary aerosol Supplementary Site (S1) were evaluated. S1 instrumentation was deployed within $0.75 \mathrm{~km}$ of the ENA Central Facility (C1) for approximately one year. Two time periods, one during the summer and one during the winter, were examined in support of the Aerosol and Cloud Experiments in the Eastern North Atlantic (ACE-ENA) intensive operating periods (IOPs) in 2017 and 2018.

As the criteria for identifying regionally representative data varies based on the specific needs of the user, we present and discuss different strategies using measured aerosol properties and their associated meteorological parameters to isolate periods in AOS data that were impacted by local aerosol at ENA. We identify high-concentration aerosol events at ENA using submicron number concentrations, size distributions, high-time-resolution measurements, and diurnal profiles. An improved understanding of local aerosol to select the optimal aerosol mask was obtained with an understanding of local meteorology during the different seasons. We developed a mathematical algorithm that employs AOS data to mask high-concentration aerosol events at ENA. We validated the ENA Aerosol Mask with aerosol data from C1 and S1 and associated meteorological data. The Supplementary Site was ideal to understand and constrain local aerosol sources within the region. In its absence, collocated data from the ENA AOS could be used to select appropriate parameters to develop an aerosol mask that would limit over- or underestimating the regional baseline aerosol data.

When available, associated metadata, such as airport flight logs and visual identification with AOS cameras should also be used to validate the application of an aerosol mask at a new site. Our results confirm the importance of optimizing an aerosol mask prior its application. In the future, the application of an aerosol mask at ARM observatories and during mobile deployments could be used to increase the data quality of continuous AOS data and to reduce uncertainties when parameterizing regional aerosol processes and impacts on clouds for incorporation in models. 


\section{Acronyms and Abbreviations}

AAF

ACE-ENA

$\mathrm{AMF}$

AOS

ARM

asl

ENA

ENA-AM

C1

CPC

DOE

$D_{p}$

G1

IOP

MET

$N_{A c}$

$N_{A t}$

$N_{L A}$

$N_{\text {tot }}$

S1

SMPS

UHSAS

UTC

VAP
ARM Aerial Facility

Aerosol and Cloud Experiments in the Eastern North Atlantic

ARM Mobile Facility

aerosol observing system

Atmospheric Radiation Measurement

above sea level

Eastern North Atlantic

Eastern North Atlantic Aerosol Mask

Central Facility

condensation particle counter

U.S. Department of Energy

particle diameter

Gulfstream-159 aircraft

intensive operational period

meteorology sensor

accumulation mode number concentration

Aitken mode number concentration

large accumulation mode number concentration

total submicron number concentration

Supplementary Site

scanning mobility particle sizer

ultra-high-sensitivity aerosol spectrometer

Coordinated Universal Time

value-added product 


\section{Contents}

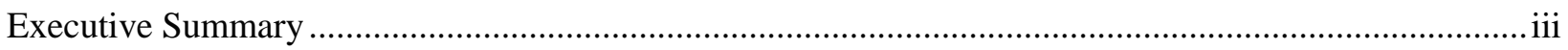

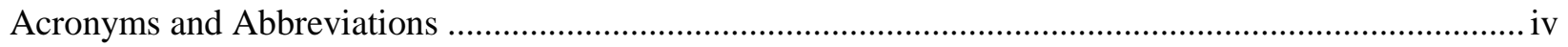

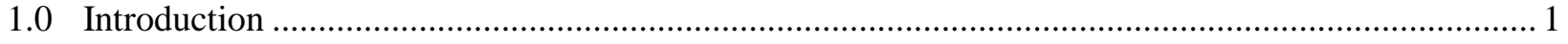

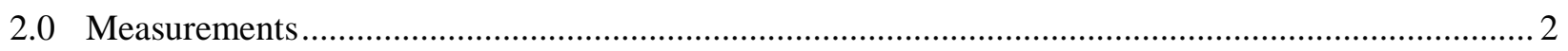

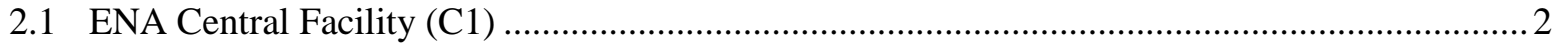

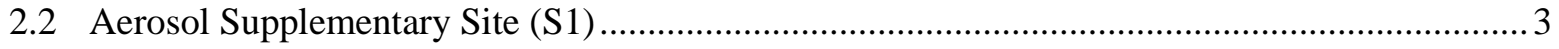

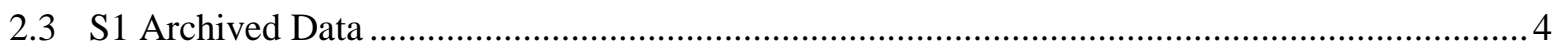

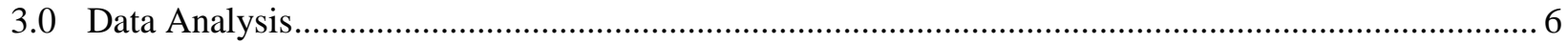

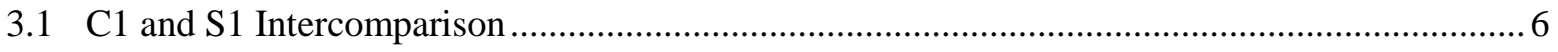

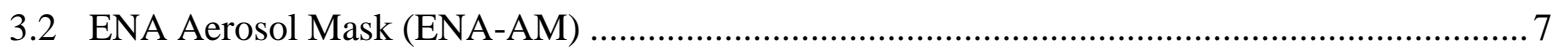

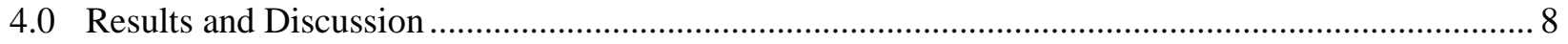

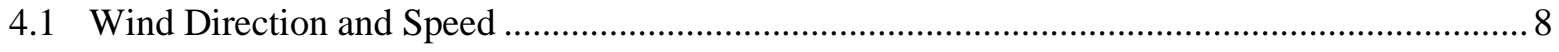

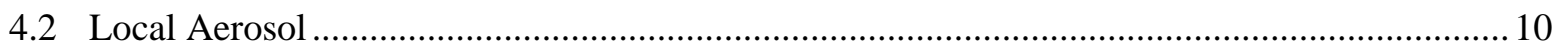

4.3 High Aerosol Number Concentrations .................................................................................. 11

4.4 Size-Resolved Submicron Aerosol....................................................................................... 13

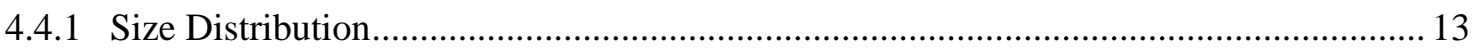

4.4.2 Submicron Aerosol Modes........................................................................................... 14

4.4.3 Variability with Wind Direction............................................................................... 16

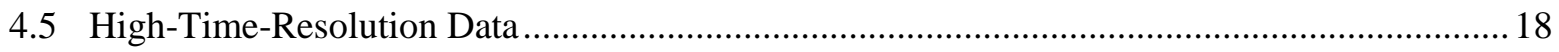

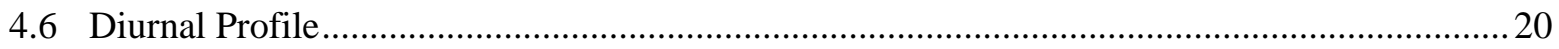

4.7 High-Number-Concentration ENA Aerosol Mask ............................................................... 22

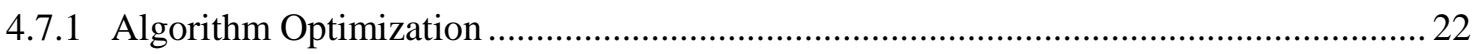

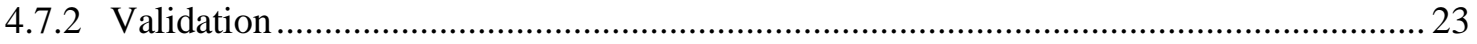

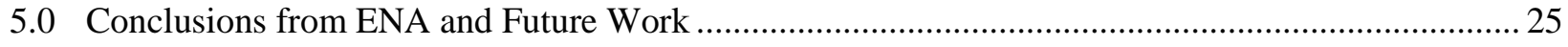

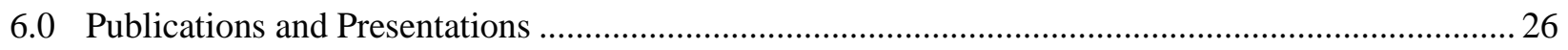

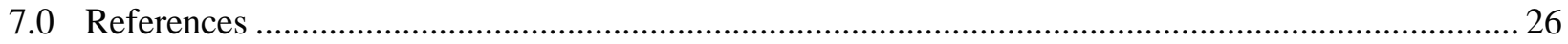




\section{Figures}

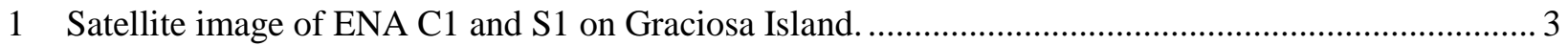

2 S1 with the aerosol inlet and Meteorology sensor located at $~ 3$ meters above the roofline. ................ 4

3 S1 inlet with funnel, insect screening, and temperature insulation attached to the larger-diameter AOS inlet during the calibration period at ENA C1 prior to deployment at S1.................................. 5

4 Surface wind rose plots in the summer at C1 (a) and S1 (b) and in the winter at C1 (c) and S1 (d).

5 Satellite image with potential aerosol sources identified in the area surrounding ENA on Graciosa Island. 10

6 Polar graphs of mean $N_{\text {tot }}$ (orange) and $N_{U H S A S}$ (blue) as a function of the wind degree direction in the summer at C1 (a) and S1 (b) and winter at C1 (c) and S1 (d).

7 Submicron aerosol size distributions at C1 (orange) and S1 (pink) during summer (a) and winter (b).

8 Box and whisker plot of $N_{A t}, N_{A c}$ and $N_{L A}$ at C1 (orange) and S1 (pink) in the summer (a) and winter (b). Mean (x) and median (red line).

9 Summer $N_{A t}$ at (a) C1 and (b) S1, $N_{A c}$ at (c) C1 and (d) S1, and winter $N_{A c}$ at (e) C1 and (f) S1 plotted as a function of wind direction.

10 Sample time periods of one-second $N_{\text {tot }}$ at C1 (orange) and S1 (pink) during the summer during a

(a) typical day and when (b) S1 sampled higher $N_{\text {tot }}$ aerosol events than C1

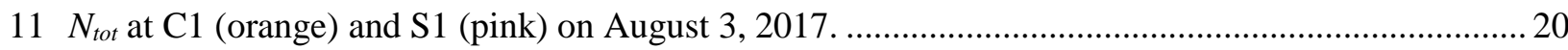

12 Box and whisker diurnal profile of $N_{\text {tot }}$ at $\mathrm{C} 1$ during summer....................................................... 21

13 Original (orange points) and masked $N_{\text {tot }}$ at $\mathrm{C} 1$ using (a) $\alpha 3-\mathrm{RW}$ (blue points) and (b) $\alpha 1-\mathrm{TP}$ (green points) input parameterizations over a 24-hour period on 8/3/2017....................................... 23

14 Scatter plot of one-minute $N_{\text {tot }}$ at C1 and S1. Original (black) and ENA-AM masked (green). .......... 24

$15 N_{\text {tot }}$ at C1 during an episode of long-range transport of continental air masses, original (black) and masked (orange) CPC data using ENA-AM.......

\section{Tables}

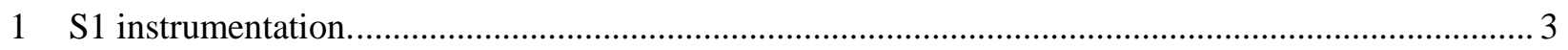

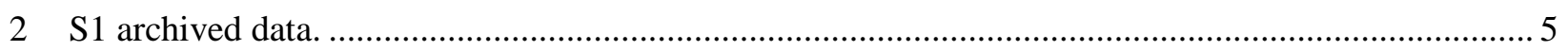

3 Percentage of time sampled as a function of wind direction during summer and winter at C1

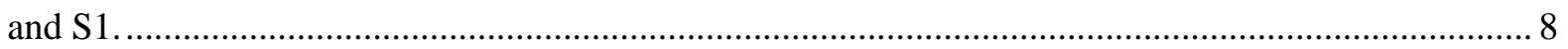

4 Potential aerosol sources identified at ENA as a function of wind direction at C1 and S1............... 11

5 Standard deviation algorithm input parameters tested at C1 and S1 in the summer.......................... 22 


\subsection{Introduction}

The U.S. Department of Energy's (DOE) Atmospheric Radiation Measurement (ARM) user facility provides high-time-resolution measurements of in situ aerosol properties and clouds at under-sampled locations worldwide. ARM collects data to investigate the direct impacts and interactions between clouds and aerosol to improve their representation in models (Mather and Voyles 2013, McComiskey and Ferrare 2016). When selecting a new location for an atmospheric observatory or mobile facility, ARM chooses locations with minimal local aerosol and trace gas sources because they are known to interfere with the measurement of regional and large-scale atmospheric aerosol processes. In addition to the inherent inability to avoid all local aerosol sources, logistical and operational needs often further constrain the selection of a site. Examples of competing needs when selecting a site include the requirement for large, flat, open spaces to locate radars and the requirements for power and infrastructure to operate the site. In this report, we use the ARM observatory in the Eastern North Atlantic (ENA) as a case study to identify when the measurements at an ARM aerosol observing system (AOS) are impacted by local aerosol sources.

The ENA location was selected by ARM to improve comprehensive long-term measurements of marine boundary-layer aerosol and low clouds in high-latitude marine environments. The first ARM deployment to ENA was with the first ARM Mobile Facility (AMF1) from April 2009 to December 2010. Based on the results from the Clouds, Aerosol, and Precipitation in the Marine Boundary Layer (CAP-MBL) field campaign (Wood et al. 2015, 2016), the current ENA observatory was established in 2013 to continue the research on aerosol-cloud-precipitation interactions on marine stratocumulus clouds (Dong et al. 2014, Logan et al. 2014, Feingold and McComiskey 2016). The ENA observatory is located on Graciosa Island, the northernmost island within the central group of islands in the Azores. It is the second smallest in size with an area of $\sim 61 \mathrm{~km}^{2}$ and is one of the least populated islands within the Azores Archipelago, with a population of less than 5,000 people. The ENA Central Facility (C1) is located on the north side of the island and is equipped with an AOS. The AOS provides a unique data set for this region of high-temporal-resolution measurements of in situ aerosol optical, physical, and chemical properties and their associated meteorological parameters (Uin et al. 2019).

In July 2017, ARM established a temporary aerosol Supplementary Site (S1) within $1 \mathrm{~km}$ of C1 to constrain local aerosol sources at ENA and to understand their pervasiveness within the region. A subset of AOS instruments was deployed for a period of approximately one year to identify the local impacts at $\mathrm{C} 1$ and to investigate whether an alternative location would be more optimal for the AOS. The deployment of measurements at S1 was planned to coincide with the Aerosol and Cloud Experiments in the Eastern North Atlantic (ACE-ENA) field campaign that occurred from June 2017 to February 2018 (Wang et al. 2019a, 2019b). During ACE-ENA, the ARM Aerial Facility (AAF) Gulfstream-159 (G-1) collected data during flights over Graciosa Island and C1 to study the vertical distribution of aerosol within the boundary layer. S1 measurements were collected continuously during the latter portion of the first ACE-ENA intensive operational period (IOP) from June to July of 2017 and during the entire second IOP from January to February of 2018. C1, S1, and AAF data can be used during these periods to constrain when C1 AOS data is regionally representative of aerosol concentrations at the ground level and when they represent aerosol concentrations that are well mixed within the boundary layer. 
Time periods impacted by local aerosol sources can convolute the study of regional aerosol processes and aerosol-cloud-precipitation interactions. For this reason, it is desirable to identify nearby sources and to mask the impacted periods to isolate the regionally representative data for subsequent analysis. One advantage of collecting high-time-resolution aerosol data with the AOS is that it is possible to sub-select the regionally representative data for subsequent analysis without losing a large fraction of the data. Post-processing methods to identify and mask high-concentration aerosol events can be implemented to achieve such goals. The challenge, however, is to accurately identify and mask the time periods impacted by local aerosol sources without also masking the desired regionally representative data. Validation of an aerosol mask can be achieved with local observations, collocated and nearby aerosol, trace gas, and metadata.

Mathematical algorithms that evaluate the statistically different behavior of adjacent data points have been found to be effective for masking real-time atmospheric data affected by local aerosol events in otherwise clean environments (Brantley et al. 2014, Hagler et al. 2012). Recent efforts to detect and isolate local high-aerosol concentration events in high time resolution include work by Hagler et al. (2012) and Drewnick et al. (2012). At ENA, Zheng et al. (2018) used AOS data to create a mask for local aerosol when the rate of change in the submicron aerosol number concentration exceeded $60 \mathrm{~cm}^{-3} \mathrm{~s}^{-1}$ to study seasonal aerosol-cloud interactions. Other methods under development at ENA include the application of machine learning by the External Data Center (XDC) group at Brookhaven National Laboratory to identify periods in AOS data that were impacted by local combustion sources due to aircraft and runway operations at the Graciosa airport (Mitchell et al. 2017). Two motion-activated cameras have been deployed at ENA and can be used to validate periods identified by machine learning or other methods such as those presented here to identify local aerosol sources using AOS data. Once identified and validated, AOS data can be masked to exclude time periods known to be impacted by local sources.

We investigate the data from C1 and S1 at ENA to: (1) provide guidance for using ENA AOS data and (2) to inform other current and future measurements across the ARM facility that may be impacted by local aerosol high-concentration events. Since identifying and masking local aerosol can be complicated to implement accurately and precisely, we evaluate several methods that can be employed. We also provide guidance for validation and future applications based on what we learned from the ENA S1 deployment.

\subsection{Measurements}

\subsection{ENA Central Facility (C1)}

The ENA Central Facility (C1) is located on Graciosa Island within the Azores Archipelago at 39 5' 28' $\mathrm{N}, 28^{\circ} 1^{\prime} 36^{\prime}$ ' W. C1 is located on the northern part of the island because the area is flat, has access to local power, and is mostly unpopulated (Figure 1).

High-temporal-resolution measurements (seconds to minutes) of aerosol properties at C1 are made with the ENA AOS. The AOS at ENA C1 includes instruments for measuring aerosol optical, physical, and chemical properties, trace gases, and meteorological measurements (McComiskey and Ferrare 2016). More complete information on the AOS can be found in Uin et al. (2019). Briefly, the AOS comprises one container housing a suite of aerosol and trace-gas instrumentation connected by sampling lines to a central inlet located approximately $10 \mathrm{~m}$ above ground level (Bullard et al. 2017). 


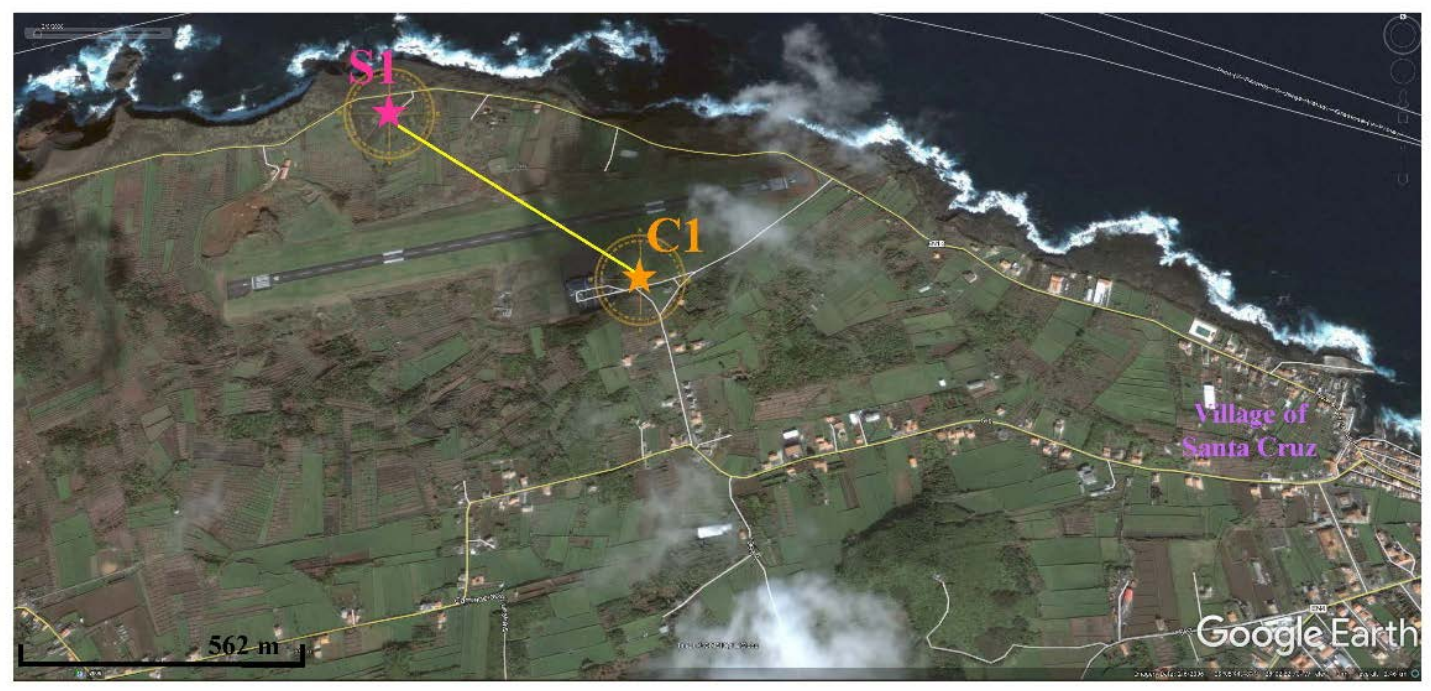

Figure 1. Satellite image of ENA C1 and S1 on Graciosa Island (Azores, Portugal).

\subsection{Aerosol Supplementary Site (S1)}

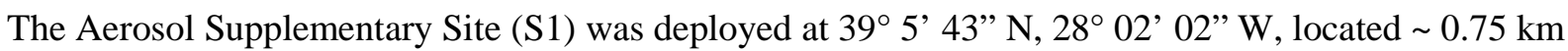
from C1 (Figure 1). The location for S1 was limited to an area $<1 \mathrm{~km}$ of $\mathrm{C} 1$ to maintain the relevance of the S1 data to that at C1. S1 was located closer to the shore than $\mathrm{C} 1$ at $\sim 0.2 \mathrm{~km}$ from the shore and at $\sim 50 \mathrm{~m}$ above sea level (asl).

Three instruments were deployed at S1, as listed in Table 1. Two aerosol instruments were selected for their ability to measure submicron aerosol concentrations in high time resolution. The third instrument was included to associate the measurements with meteorological parameters as is done in the AOS. Measurements were designed to duplicate those made within the AOS as closely as possible without the use of an AOS inlet at S1. The instruments deployed were duplicate models of those used within the AOS at $\mathrm{C} 1$.

Table 1. S1 instrumentation.

\begin{tabular}{lll}
\hline Instrument & Manufacturer and Model & Handbook \\
\hline $\begin{array}{l}\text { Condensation particle counter } \\
\text { (CPC), fine mode }\end{array}$ & $\begin{array}{l}\text { TSI, Inc., Shoreview, Minnesota, } \\
\text { Meteorology sensor (Met) }\end{array}$ & USA; Model 3772 \\
$\begin{array}{ll}\text { Ultra-high-sensitivity aerosol } \\
\text { spectrometer (UHSAS) }\end{array}$ & $\begin{array}{l}\text { Droplet Measurement Technologies, } \\
\text { Inc., Longmont, Colorado, USA }\end{array}$ & (Uin 2016) \\
\hline
\end{tabular}

More detailed information on the instruments can be found online in the ARM instrument handbooks listed in the table above. Briefly, the fine-mode condensation particle counter (CPC) measures the submicron number concentration $\left(N_{\text {tot }}\right)$ of aerosol particles from $\sim 7 \mathrm{~nm}$ to $1 \mu \mathrm{m}$ in particle diameter $\left(D_{p}\right)$. Particles are grown by condensing butanol vapor onto the particles before they are optically counted by illuminating them with a laser beam to count the number of light pulses scattered. The meteorology 
sensor (Met) provides ambient air temperature, relativity humidity, atmospheric pressure, wind speed and direction relative to true North, and precipitation data (rain amount, duration, and intensity). The ultra-high-sensitivity aerosol spectrometer (UHSAS) is an optically scattering, laser-based aerosol particle spectrometer for sizing particles from approximately 60 to $1,000 \mathrm{~nm} D_{p}$. Aerosol particles scatter the laser light as a function of their optical $D_{p}$. The UHSAS detection efficiency is $\sim 100 \%$ for particles $>100 \mathrm{~nm}$ and for concentrations $<3,000 \mathrm{~cm}^{-3}$ (Cai et al. 2008). Concentration measurement errors occur for smaller particles that have low scattered light intensities and during periods of higher $N_{\text {tot }}$ due to particle coincidence. Sizing of spherical and irregular particles by the UHSAS are within $10 \%$ of the mobility diameters measured by the scanning mobility particle sizer (SMPS) for particles with $D_{p}>70 \mathrm{~nm}$ (Cai et al. 2008). Therefore, we use the UHSAS submicron data for particles $>70 \mathrm{~nm}$ (Uin 2016). Since submicron data was collected at S1 and compared with the submicron data collected at C1, we make no inferences on supermicron aerosol.

The aerosol instruments were powered and located inside a converted garage in an unoccupied house as shown in Figure 2. The meteorology sensor was mounted above the inlet at approximately 3 meters above the roofline. A funnel with fine stainless-steel mesh was used to keep insects and rain out of the inlet. The sampling line was insulated and a Nafion ${ }^{\mathrm{TM}}$ dryer (PD Series, Perma Pure LLC, Lakewood, New Jersey, USA) was used to dry the aerosol sample line as is done in the C1 AOS (Uin et al. 2019).

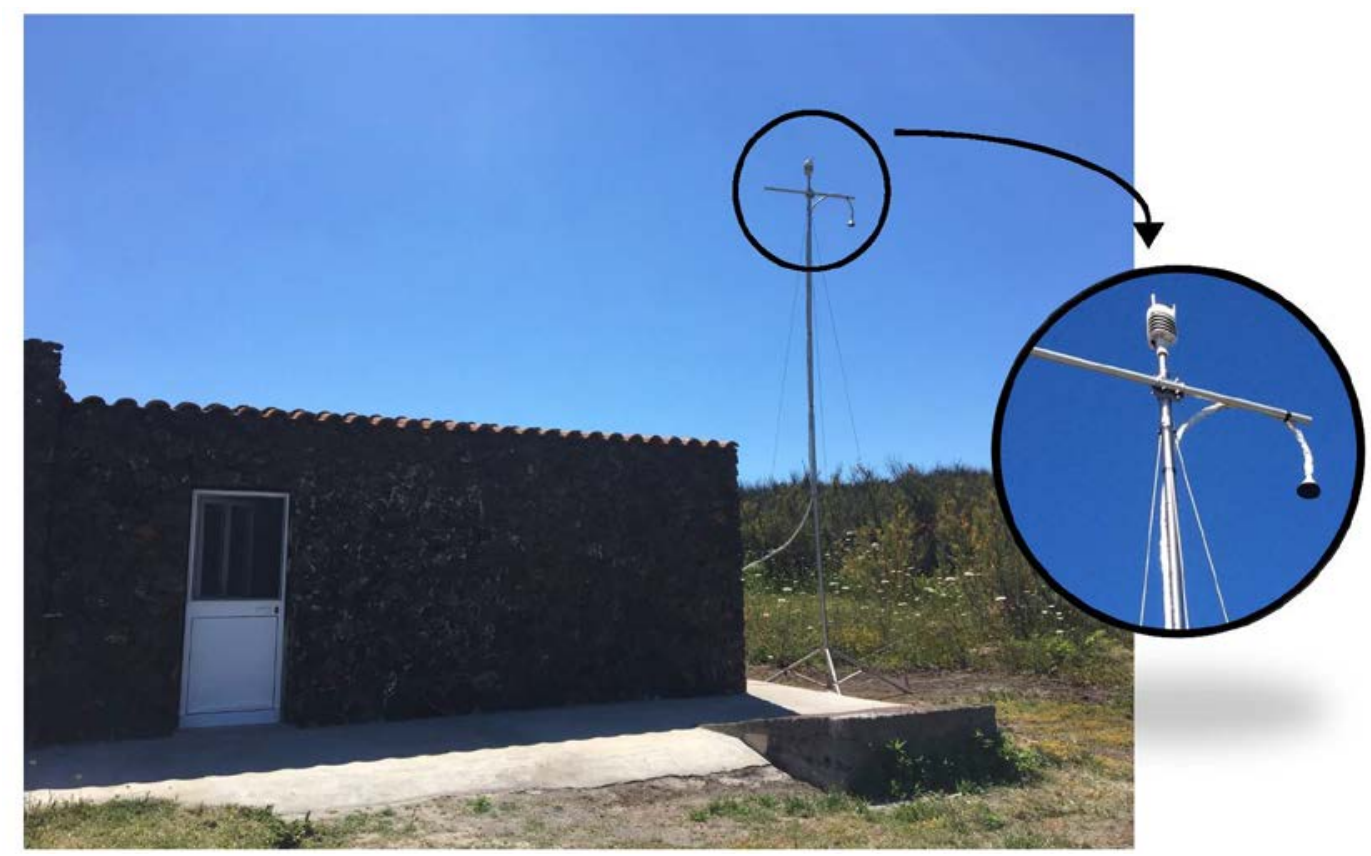

Figure 2. S1 with the aerosol inlet and Meteorology sensor located at $\sim 3$ meters above the roofline.

\subsection{S1 Archived Data}

The instruments were deployed to S1 in July 2017 with a computer to acquire data for ingest into the ARM Data Center. Data were collected at S1 until the site was decommissioned in April of 2018 after the conclusion of ACE-ENA. S1 data can be found at the ARM Data Center in the same way as data collected at C1. Table 2 lists the details of the measurements that were made at S1. The ARM Data Discovery tool is available at https://www.archive.arm.gov/discovery/ for users to freely download the data. The facility 
names in the Data Center are the same as those used in this report, ENA C1, and ENA S1. Data from the S1 instruments are listed as evaluation data using the ARM standard AOS names: AOSCPCF, AOSMET, AOSUHSAS. All data presented here are in Coordinated Universal Time (UTC), the same as it is reported at the ARM Data Center. Local time is the same as UTC at ENA in the summer and is offset by one hour in the winter (UTC-1). We used the highest level of data available in the ARM Data Center at the time of this report, except when indicated otherwise in the text.

Table 2. S1 archived data.

\begin{tabular}{|c|c|c|}
\hline Datastream & Measurement & Archived Data \\
\hline AOSCPCF & $\begin{array}{l}\text { Submicron aerosol number concentration, } N_{\text {tot }} \\
\left(D_{p} \sim 7 \mathrm{~nm}-1 \mu \mathrm{m}\right)\end{array}$ & 7/20/17-8/23/17 \\
\hline AOSMET & $\begin{array}{l}\text { Wind speed and direction, ambient air relative } \\
\text { humidity, temperature, atmospheric pressure, } \\
\text { rain amount, duration, and intensity }\end{array}$ & 7/20/17-4/16/18 \\
\hline AOSUHSAS & $\begin{array}{l}\text { Aerosol number concentration, } N_{U H S A S} \\
\text { Aerosol size distribution } \\
\left(D_{p} \sim 70 \mathrm{~nm}-1 \mu \mathrm{m}\right)\end{array}$ & 7/19/17-3/2/18 \\
\hline
\end{tabular}

Prior to deployment at S1, the instruments were calibrated at C1 alongside the AOS instruments. The inlet for S1 was attached to the AOS inlet for a direct comparison of the collocated S1 instruments (Figure 3). The aerosol inlet configuration was the same as when it was deployed at S1, with the downturned inlet, funnel, stainless-steel screening, tubing insulation, and Nafion ${ }^{\mathrm{TM}}$ dryer. Aqueous solutions of monodisperse polystyrene latex spheres (PSLs, Thermo Scientific, Waltham, Massachusetts, USA) of $100 \mathrm{~nm}, 203 \mathrm{~nm}, 400 \mathrm{~nm}$, and $498 \mathrm{~nm} D_{p}$ were atomized with an aerosol generator (model 3079A, TSI, Inc.) and measured by the collocated UHSASs. Ambient data from the CPCs, meteorology sensors, and UHSASs were compared over a period of one week after the S1 inlet flow rate was optimized to minimize submicron particle loss (Bullard et al. 2017).

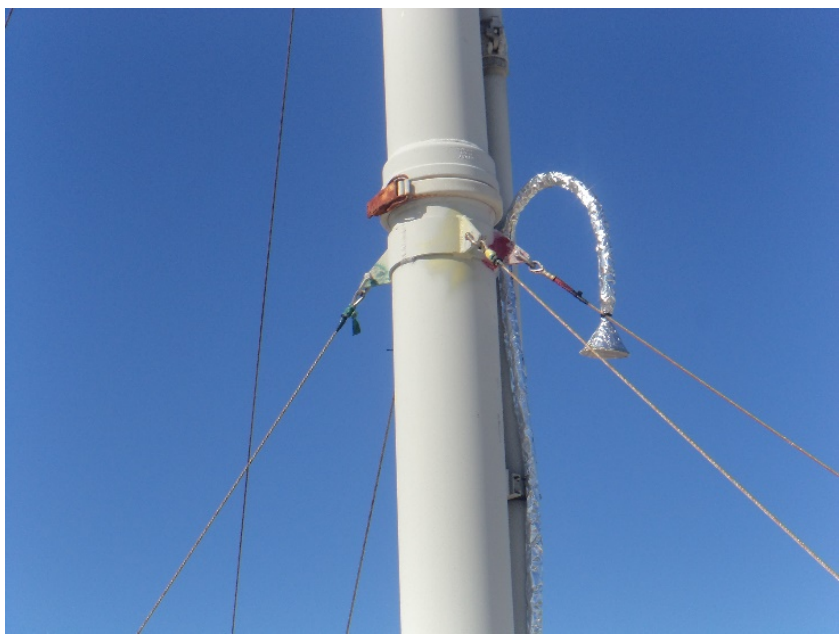

Figure 3. S1 inlet with funnel, insect screening, and temperature insulation attached to the larger-diameter AOS inlet during the calibration period at ENA C1 before deployment at S1. 


\subsection{Data Analysis}

\subsection{C1 and S1 Intercomparison}

We present and evaluate different strategies to identify periods when the AOS data were impacted by high concentrations of submicron aerosol. We associate them with known local potential aerosol sources. Different methods to identify and validate these periods are discussed as the specific needs for applying an aerosol mask to the data will depend on the specific science goals of the data user.

The impact of local aerosol sources at ENA C1 were evaluated by comparing data collected at C1 and S1. Two one-month periods were selected for detailed analysis representing two different seasons: summer (7/22/17-8/20/17) and winter (12/01/17-12/30/17). We focused on the data from the CPC, UHSAS, and meteorology sensor since a direct comparison could be made between C1 and S1. The CPC and UHSAS provide aerosol number concentrations and size distributions that can detect high-number-concentration aerosol events in high time resolution.

Measurements from the USHAS and CPC were combined to describe the submicron aerosol size distribution by dividing the data into three optical size modes. Zheng et al. (2018) used lognormal fitting of the submicron aerosol size distributions from the UHSAS to define three modes to study aerosol-cloud interactions at ENA. The lognormal fittings gave three parameters: mode diameter, mode number concentration, and mode $\sigma$ (Table 2 in Zheng et al. 2018). Number concentrations ( $N$ ) of the fitted modes were classified by the mode diameter as:

- $N_{A t}=$ Number concentration of Aitken (At) mode aerosol $\left(D_{p} \leq 100 \mathrm{~nm}\right)$

- $N_{A c}=$ Number concentration of Accumulation (Ac) mode aerosol $\left(D_{p}=100-300 \mathrm{~nm}\right)$

- $N_{L A}=$ Number concentration of Large Accumulation (LA) mode aerosol ( $\left.D_{p}=300-1,000 \mathrm{~nm}\right)$

Number concentrations of Ac and LA mode, $N_{A c}$ and $N_{L A}$, were defined as the corresponding fitted mode number concentrations. The $N_{A c}$ and $N_{L A}$ mode number concentrations reported here are directly measured by the UHSAS. Since there was not a direct measurement of the full range of At mode aerosol, $N_{A t}$ was determined by combining the measurements from the CPC and the UHSAS. $N_{A t}$ was calculated as the difference between the total submicron number concentration $\left(N_{t o t}\right)$ as measured by the CPC and the sum of the UHSAS number concentrations from the two larger modes: $N_{A t}=N_{t o t}-\left(N_{A c}+N_{L A}\right)$. All $D_{p}$ referenced in the text refer to aerosol optical diameter unless they are stated as otherwise.

One way to determine statistical outliers in data is by comparing the difference between the median and the mean values. Time periods when the median and mean $N_{\text {tot }}$ differ significantly are used to indicate periods when the data was affected by outlying events, such as high-number-concentration aerosol events. Median values represent the midpoints in the data, which are minimally affected by outlying events. Mean values describe the central tendency of the data and are affected by the outlying events. As such, comparison between the two values provided information about the variability within the overall data set. The use of the term outlier here is restricted to high-aerosol $N_{\text {tot }}$ events as incorrect and missing data and their flags (e.g., negative values and -9999) were removed prior to the analysis presented here. Significant deviations between the mean and median $N_{\text {tot }}$ where the mean was biased high were used to indicate when aerosol $N_{\text {tot }}$ had a statistically relevant higher variability due to the presence of high-concentration aerosol events. 


\subsection{ENA Aerosol Mask (ENA-AM)}

To isolate high-concentration aerosol events, we develop and apply a mathematical algorithm to ENA $N_{\text {tot }}$ data. Development of the ENA Aerosol Mask (ENA-AM) includes the application of an optimized standard deviation algorithm plus additional constraints. Standard deviation algorithms have been applied to aerosol data previously (Drewnick et al. 2012). To correctly apply ENA-AM required the ability to identify statistically different behavior between adjacent data points in the $N_{\text {tot }}$ data collected by the AOS at C1 or the CPC at S1. At ENA, low-aerosol $N_{\text {tot }}$ periods represent the baseline measurements, and the short-duration, high-concentration periods were identified as local aerosol events. To apply ENA-AM, the time resolution of the data had to be shorter than the typical time period of the high-concentration events, and the variation within the clean baseline periods had to be smaller than the variation of $N_{\text {tot }}$ during the high-concentration events. Therefore, the ENA-AM works best with high-time-resolution data, as is collected by the AOS at time intervals on the order of seconds to minutes, and for identifying local sources that have high temporal variability. An additional requirement for ENA-AM is that at least half of the total data points have to be representative of the baseline conditions. The one-minute $N_{\text {tot }}$ data collected at $\mathrm{C} 1$ and $\mathrm{S} 1$ fulfill these requirements, and we therefore developed ENA-AM as described below using two one-month periods of data collected at ENA.

We used the data below the median to determine the standard deviation of the baseline $\left(\sigma_{\mathrm{b}}\right)$ for $N_{\text {tot }}$. Data that differed by more than $\alpha$ times the $\sigma_{\mathrm{b}}$ from the adjacent baseline data were identified and masked as being impacted by high-concentration aerosol events, while the remaining data points were defined as the baseline data. The variable $\alpha$ was used to set the threshold, and its value was defined as a function of the specific data set and time series variability. An alternative technique would have been to use the standard deviation of the data that were between the first and the third quartiles. While this alternative was not explored here, we expect that it would yield similar results to ENA-AM.

Whenever a data point was identified to be greater than the defined threshold, the next point in the time series was evaluated using a random walk method: threshold $\left.=\left(\sigma_{b}+\operatorname{sqrt}(n)\right) * \alpha\right)$, where $n$ is the number of data points since the last data point that was within the standard variability. In this way, the threshold level was slightly increased to account for a normal temporal development of the baseline. If the density of the high-concentration particle events is high, the algorithm is not well suited to accurately identify the baseline variability properly. In such cases, $\alpha$ should be set to a lower value, and the random walk method threshold might be better substituted with a two-point thresholding method that includes the two data points after each outlying data point to be a part of the same event. Thus, the value of $\alpha$ and the thresholding method are dependent on the time series variability, as is the selection of the time period over which to apply ENA-AM. These parameters must be optimized for the specific data set to mask outlying events.

We tested different $\alpha$ values and thresholding methods to optimize ENA-AM for the one-minute time resolution $N_{\text {tot }}$ data at ENA. In addition to optimizing ENA-AM algorithm parameters, we also included in ENA-AM the outlying events in $N_{\text {tot }}$ between the 99th and 100th percentile. Data from the AOS masked with ENA-AM are presented with observations and metadata to validate their application to $N_{\text {tot }}$ at ENA. 


\subsection{Results and Discussion}

\subsection{Wind Direction and Speed}

The percentages of time that the wind was sampled as a function of the four cardinal and four intercardinal wind directions are reported in Table 3. During the summer and winter at C1 and S1, the winds dominantly came from the south and southwest. Minimal time periods were sampled when the wind was from the north and northwest.

During the summer, C1 and S1 were dominated by winds from the southwest at 27.6\% (C1) and 32.8\% (S1) of the time. At C1, winds from the east at $14.6 \%$ and southeast at $15.0 \%$ were the next-most-dominant directions sampled. At S1, winds from the east were also the next-most sampled at $21 \%$ of the time, while the southeast wind direction was sampled less often at $8.2 \%$ of the time. Winds from the north and northwest were the least frequently observed at both locations. Winds from the north were sampled $7.3 \%(\mathrm{C} 1)$ and $6.9 \%(\mathrm{~S} 1)$ of the time and from the northwest at $6.7 \%(\mathrm{C} 1)$ and $5.6 \%(\mathrm{~S} 1)$ of the time.

In the winter, the wind direction had an almost equally dominant contribution from the south, 29.0\% (C1) and $30.3 \%$ (S1) as the southwest, 30.9\% (C1) and 30.8\% (S1). At C1 the next-largest wind directions sampled were from the west at $17.6 \%$ of the time and from the southeast at $12.6 \%$ of the time. S1 differed from C1 in that while the next-most-dominant wind direction was from the southeast at $19.4 \%$ of the time, the wind from the west was significantly less at $7.4 \%$ of the time. In contrast to the summer, both sites had a negligible contribution $(\leq 12 \%)$ from the wind directions associated with the direction of the shore that equates to half of the wind rose: the northwest, north, northeast, and east. While these wind directions were also not the dominant wind directions observed during the summer, the winds were more equally distributed from this half of the wind rose in the summer at $40.3 \%$ (C1) and $41.8 \%$ (S1) by comparison.

Table 3. Percentage of time sampled as a function of wind direction during summer and winter at C1 and S1.

\begin{tabular}{ccccc}
\hline \multirow{2}{*}{ Wind Direction } & \multicolumn{2}{c}{ Summer } & \multicolumn{2}{c}{ Winter } \\
\cline { 2 - 5 } & C1 & S1 & C1 & S1 \\
\hline N & $7.3 \%$ & $6.9 \%$ & $2.4 \%$ & $2.9 \%$ \\
NE & $11.7 \%$ & $8.0 \%$ & $2.0 \%$ & $1.7 \%$ \\
E & $14.6 \%$ & $21.3 \%$ & $2.3 \%$ & $5.6 \%$ \\
SE & $15.0 \%$ & $8.2 \%$ & $12.6 \%$ & $19.4 \%$ \\
S & $6.9 \%$ & $10.6 \%$ & $29.0 \%$ & $30.3 \%$ \\
SW & $27.6 \%$ & $32.8 \%$ & $30.9 \%$ & $30.8 \%$ \\
W & $10.3 \%$ & $6.5 \%$ & $17.6 \%$ & $7.4 \%$ \\
NW & $6.7 \%$ & $5.6 \%$ & $3.2 \%$ & $1.9 \%$ \\
\hline
\end{tabular}

The frequency of the wind speeds sampled at ENA are shown as a function of wind direction in Figure 4. In general, the surface wind speed was higher at C1 than at S1, independent of the season. In the summer (Figures $4 \mathrm{a}$ and $4 \mathrm{~b}$ ), surface wind speed mean values and their one standard deviation were $4.7 \pm 2.3 \mathrm{~m} \mathrm{~s}^{-1}$ (C1) and $3.2 \pm 1.6 \mathrm{~m} \mathrm{~s}^{-1}(\mathrm{~S} 1)$. The maximum wind speed measured during the summer came from the southwest for both sites at $15.2 \mathrm{~m} \mathrm{~s}^{-1}$ (C1) and $10.0 \mathrm{~m} \mathrm{~s}^{-1}$ (S1). 
In the winter (Figures 4c and 4d), the mean wind speed at ENA was approximately double the speed recorded in the summer. The mean wind speed and standard deviation recorded were $7.3 \pm 2.5 \mathrm{~m} \mathrm{~s}^{-1}$ (C1) and $5.7 \pm 2.0 \mathrm{~m} \mathrm{~s}^{-1}$ (S1). The peak wind speed measured during the winter was from the same direction as during the summer, from the southwest. The wind speed peaked at $21.7 \mathrm{~m} \mathrm{~s}^{-1}(\mathrm{C} 1)$ and at $16.6 \mathrm{~m} \mathrm{~s}^{-1}(\mathrm{~S} 1)$.

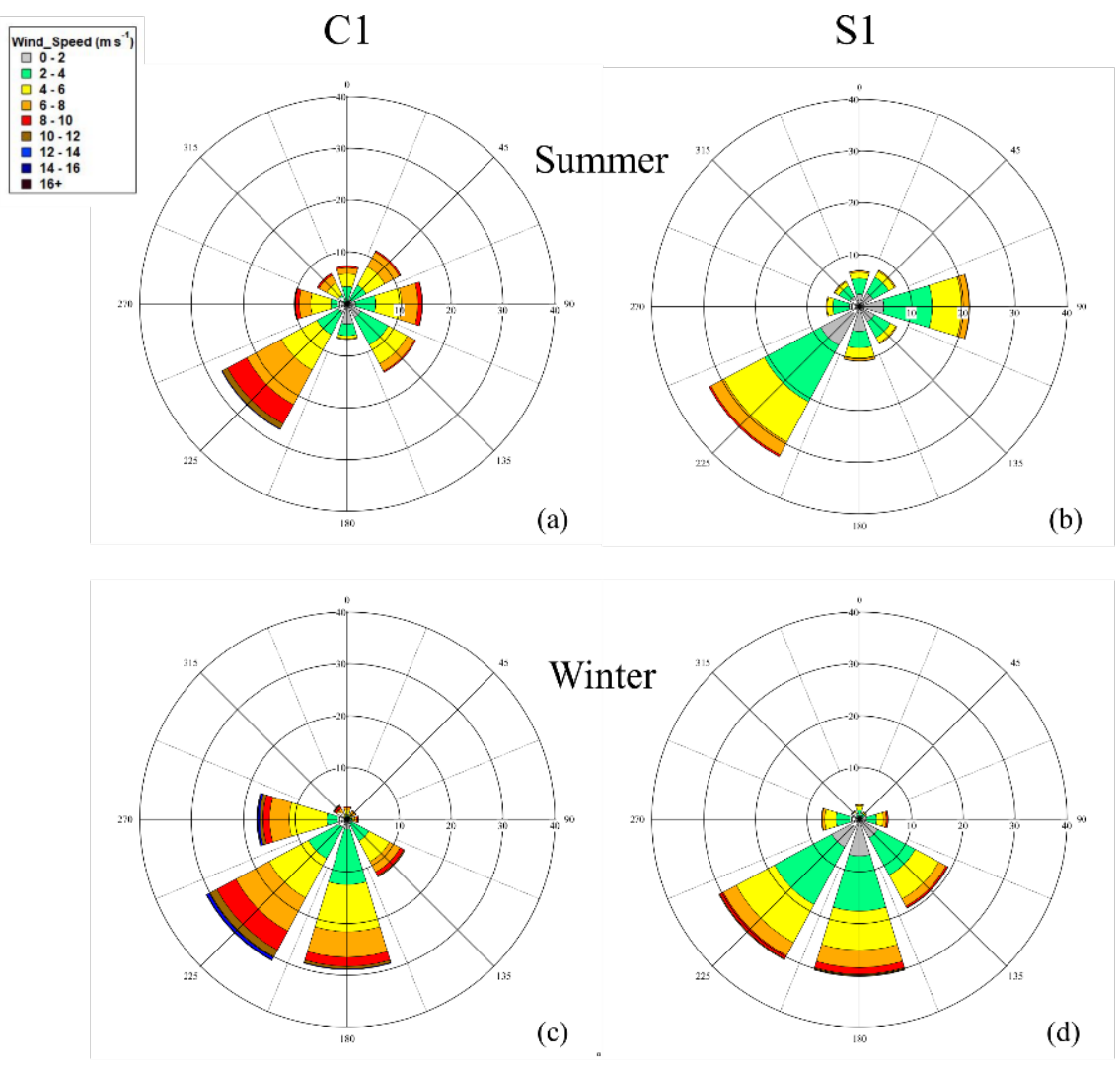

Figure 4. Surface wind rose plots in the summer at $\mathrm{C} 1$ (a) and $\mathrm{S} 1$ (b) and in the winter at $\mathrm{C} 1$ (c) and S1 (d). The length of the radial bars is the frequency of different wind speed ranges shown in color as a percentage of the time sampled.

The mean wind speed observed at C1 and S1 were within 25\% of each other during the summer and winter. The wind speed at C1 was higher during both seasons. S1 mean winds were $68 \%$ and $78 \%$ of C1 in the summer and winter respectively. The observed maximum wind speed coincided with the dominant wind direction at $\mathrm{C} 1$ and S1 in both seasons. This observation was most evident in the summer when the wind was largely dominated by winds from the southwest. During the winter, there was a similar fraction of wind that originated from the south and the southwest with overall higher wind speeds at both sites.

Overall, C1 and S1 experienced similar dominant wind directions and mean wind speeds. We therefore expect C1 and S1 to exhibit similar trends in the aerosol data with the exception of periods when they are impacted by local aerosol sources. We expect those periods to be influenced by the proximity and direction of the aerosol source in relation to the measurement site. 


\subsection{Local Aerosol}

While Graciosa Island and the location for C1 were selected due to the remote location and minimal population, the Graciosa regional airport is nearby. The airport hosts two flights a day throughout the year, with one in the late morning or early afternoon and the other in the late afternoon. The largest town near C1 is Santa Cruz, which is $\sim 1.8 \mathrm{~km}$ to the southeast with a population of $\sim 1,000$. We identify potential local aerosol and trace gas sources associated with the airport and other local activities that may be relevant to ENA on a satellite image of the northeast section of Graciosa Island in Figure 5.

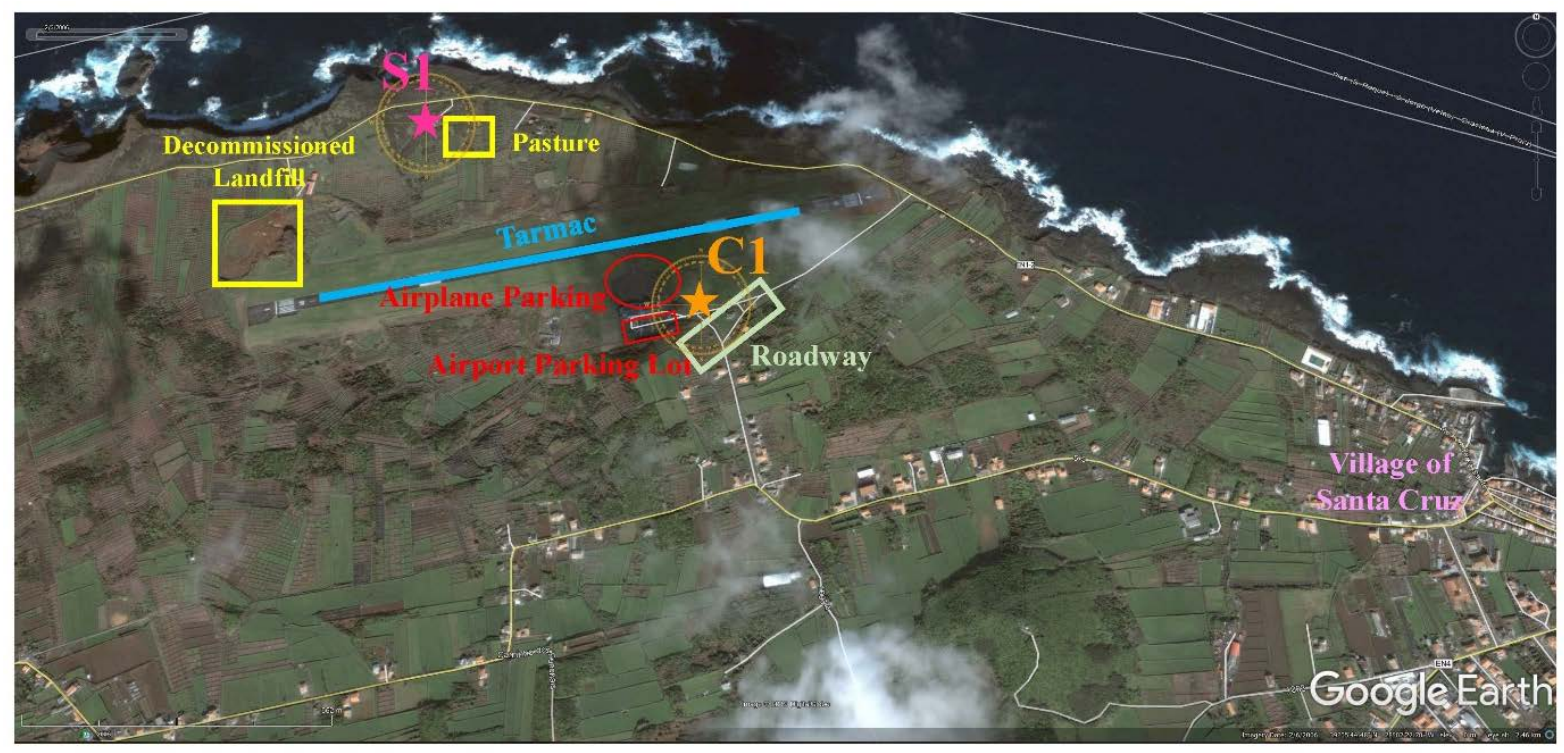

Figure 5. Satellite image with potential aerosol sources identified in the area surrounding ENA on Graciosa Island.

The airport runway is located to the north of C1, spanning from the west to the northeast with regards to C1. The terminal building with one gate is located to the west. The airport parking lot is southwest of C1 and the aircraft parking area is to the west. The town of Santa Cruz is connected to the airport via the road to the east and south of C1.

S1 was located on the other side of the airport runway with respect to $\mathrm{C} 1$. As such, the runway was located to the south of S1, spanning from the southwest to the southeast. A rural road close to the shoreline was located to the north. An additional potential aerosol source at S1 included a pasture where cattle were observed to the east and southeast. A mobile diary unit with a diesel engine was also observed on occasion in operation in association with the cattle. When present, the mobile dairy was observed to operate two times a day for about an hour.

Identifying local aerosol at ENA based on the proximity and wind direction of the source relative to the measurement site was complex since the sources originated over a wide variety of wind directions. We attempted to summarize the known potential local aerosol sources in Table 4 as a function of their primary wind direction with regard to $\mathrm{C} 1$ and S1. Four nearby potential aerosol sources were identified at C1: the airport runway from the west to northeast, the road that connects Santa Cruz to the airport from east to south, the airport parking lot to the southwest, and the airplane parking area to the west. At S1, the airport runway spans from the east to south and the rural road spans from the west to northeast. These 
were the two closest potential aerosol sources at S1. Additional potential sources near S1 included the pasture from the southeast to south and a decommissioned land fill with active vents to the southwest.

Table 4. Potential aerosol sources identified at ENA as a function of wind direction at C1 and S1.

\begin{tabular}{lll}
\hline Wind & \multicolumn{2}{c}{ Potential Aerosol Sources near ENA } \\
\cline { 2 - 3 } Direction & C1 & S1 \\
\hline N & Airport runway & Rural road \\
NE & Airport runway & Rural road \\
E & Road & Airport runway, rural road, pasture \\
SE & Road & Airport runway, pasture, airplane and car parking, road \\
S & Road & Airport runway \\
SW & Airport parking lot & Airport runway, decommissioned landfill \\
W & Airport runway, airplane parking & Rural road \\
NW & Airport runway & Rural road \\
\hline
\end{tabular}

Throughout the report, activities associated with the Graciosa airport that may impact aerosol measurements at ENA are collectively referred to as airport operations. Four known potential sources were identified: aircraft assistance, runway maintenance, the airport parking lot, and the road to the airport. While this is by no means an exhaustive list, further details on these airport activities at ENA are presented here. Diesel-engine vehicles assist aircraft operations before, during, and after landing and take-off. They assist with the loading and unloading of passengers and luggage during all stages before, during, and after the plane's time on the ground. Large vehicles with diesel engines are typically driven and parked several times daily in open spaces designated for plane loading and unloading to maintain the runway and in front of the airport terminal building. Once a day, between approximately 7:45 and 8:30 UTC, three trucks leave the warehouse west of the airport terminal building, and travel the length of the runway several times over a period of approximately 20 to 25 minutes before returning to the warehouse. The parking lot to the southwest of the airport is used mostly when planes arrive and depart and to a lesser degree throughout the operational period of the airport. External to the airport, but still related, is the road that connects the town of Santa Cruz to the airport through an intersection located between the east and south side of the $\mathrm{C} 1$ site. While the area is rural, traffic is generally low, and there are no stoplights, increased traffic occurs before arrival and after departure of aircraft at the airport.

\subsection{High Aerosol Number Concentrations}

Wind direction can be used with aerosol measurements to determine aerosol sources (Zhou et al. 2016). To understand the frequency and direction from which local aerosol originated at ENA we present mean aerosol $N_{\text {tot }}$ and $N_{U H S A S}$ as a function of wind direction. $N_{\text {tot }}$ and $N_{U H S A S}$ at C1 and S1 were used to understand the directional and temporal influence of observed high aerosol number concentrations at two locations and to evaluate the use of wind direction data to create an aerosol mask at ENA.

In Figure 6, one-minute $N_{\text {tot }}$ and $N_{\text {UHSAS }}$ were averaged as a function of wind degree direction in summer and winter. When plotted by wind degree direction, we observed $N_{\text {tot }}>1,000 \mathrm{~cm}^{-3}$ at C1 and S1. Mean $N_{\text {tot }}$ for all directions in the summer were $710 \mathrm{~cm}^{-3}$ (C1) and $490 \mathrm{~cm}^{-3}$ (S1). $N_{U H S A S}$ mean concentrations were less than half of $N_{\text {tot }}$ during the same time periods: $342 \mathrm{~cm}^{-3}$ (C1) and $210 \mathrm{~cm}^{-3}$ (S1). The higher $N_{\text {tot }}$ was due to a significant fraction of aerosol below the UHSAS lower detection size limit used here of 
$70 \mathrm{~nm}$ since the instruments have similar upper detection size limits. Without the $N_{\text {tot }}$ that includes $D_{p}<70 \mathrm{~nm}$, the high-concentration aerosol would be harder to identify by wind direction alone due to the lower variability observed in the $N_{U H S A S}$. For this reason, we continue our analysis by wind direction in this section by focusing on $N_{\text {tot }}$.

The largest mean $N_{\text {tot }}$ observed by wind degree direction at $\mathrm{C} 1$ were $\geq 3,000 \mathrm{~cm}^{-3}$ (Figure 6a,c). These high $N_{\text {tot }}$ concentrations were observed during summer and winter when the winds were coming from the west to northwest, which were the wind directions associated with the airport. These directions were attributed to the use of the runway and the airplane parking lot with AOS camera visual validations of aircraft. The next highest $N_{\text {tot }}$ were observed from the south to southeast at C1. $N_{\text {tot }} \geq 1,000 \mathrm{~cm}^{-3}$ were observed in the summer and $N_{\text {tot }} \geq 1,600 \mathrm{~cm}^{-3}$ in the winter. These directions were associated with the direction of the road that leads from the airport to the town of Santa Cruz.

$\mathrm{C} 1$

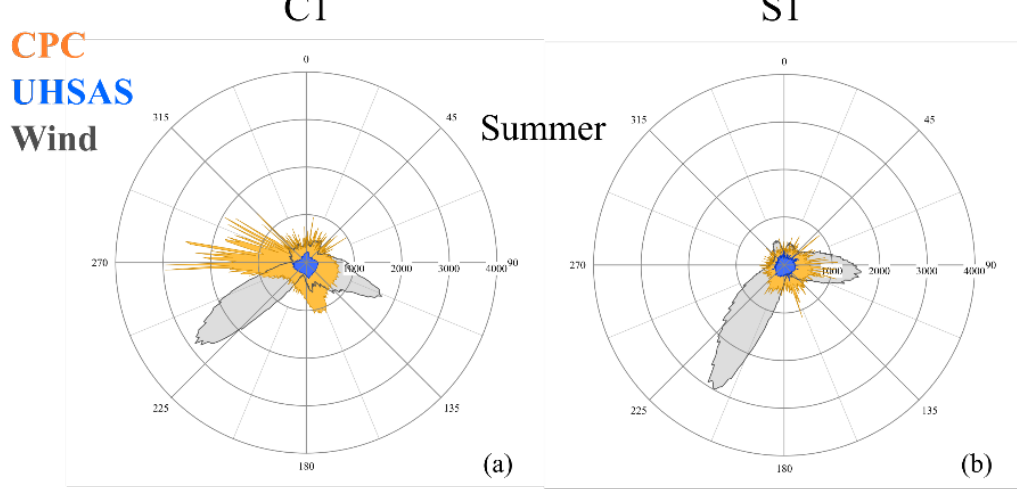

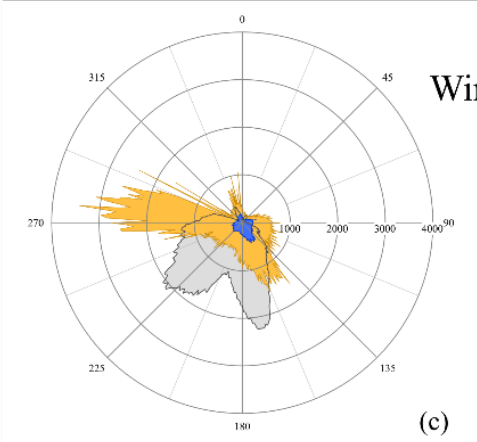

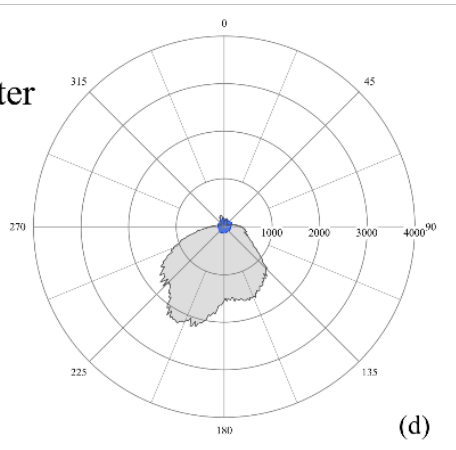

Figure 6. Polar graphs of mean $N_{\text {tot }}$ (orange) and $N_{U H S A S}$ (blue) as a function of the wind degree direction in the summer at C1 (a) and S1 (b) and winter at C1 (c) and S1 (d). The frequency of the wind direction is shown in grey.

While mean $N_{\text {tot }}$ were lower at S1 than C1, S1 also observed $N_{\text {tot }}>1,000 \mathrm{~cm}^{-3}$ (Figure 6b). The three highest $N_{\text {tot }}$ at $\mathrm{S} 1$ that were $>1,000 \mathrm{~cm}^{-3}$ were observed from the south-southeast, east-southeast, and east. The wind directions of the observed maxima $N_{\text {tot }}$ indicated that the airport runway, rural road, and pasture were most likely associated with the observed high $N_{\text {tot }}$ at $S 1 . N_{\text {tot }} \sim 1,000 \mathrm{~cm}^{-3}$ observed from the northeast were likely due to the rural road along the shore. $N_{\text {tot }} \sim 500 \mathrm{~cm}^{-3}$ from the southwest were from the direction of the decommissioned landfill and the airport runway. $N_{\text {tot }}$ was not available during the winter at S1 to make a comparison with summer. 
The results of the wind direction analysis shown here indicated that the main sources of $N_{\text {tot }} \geq 1,000 \mathrm{~cm}^{-3}$ at C1 and S1 were most likely associated with airport activities and road traffic due to the proximity and direction of the sources. However, as shown in Figure 6, high $N_{\text {tot }}$ were also observed from wind directions that we could not directly associate with the potential local sources discussed in Section 4.2. These observed high $N_{\text {tot }}$ could be due to other unattributed local sources at ENA that are not discussed here and/or the result of complex meteorological conditions known to exist in the region (Remillard et al. 2012). To provide one example of an aerosol source that we could not verify, we received conflicting information about the existence of a potential brick production facility that might exist $\sim 1 \mathrm{~km}$ to the south-southeast of C1.

In summary, C1 observed higher $N_{\text {tot }}$ over a larger range of wind directions than what was observed at S1. We attributed this difference to its closer proximity to the airport and its associated activities. While the $N_{\text {tot }}$ associated with the direction of the airport were lower at S1 than what was observed at C1, S1 had additional high $N_{\text {tot }}$ that were not observed at C1 due to sources such as the rural road and the decommissioned landfill.

\subsection{Size-Resolved Submicron Aerosol}

\subsubsection{Size Distribution}

- Submicron size distributions can be used to determine the source of observed high $N_{\text {tot }}$ since different combustion sources, fuel types, and modes of operation produce different particle sizes. For example, depending on type of jet fuel used, aircraft produce Aitken mode particles with $D_{p}<100 \mathrm{~nm}$ with $N_{\text {tot }} \sim 4,000-30,000 \mathrm{~cm}^{-3}$ (Moore et al. 2017) that have been observed to be even greater during periods of take-off and landing at $\geq 40,000 \mathrm{~cm}^{-3}$ (Campagna et al. 2016). Aerosol number concentrations from port-fuel-injection gasoline vehicles have been measured to be $\sim 10,000 \mathrm{~cm}^{-3}$ with mean $D_{p}$ between 40 and $80 \mathrm{~nm}$. $N_{\text {tot }}$ emitted by diesel engines can be as high as $10^{4} \mathrm{~cm}^{-3}$ with mean aerosol $D_{p}$ between 60 and $120 \mathrm{~nm}$, larger than those emitted by gasoline engines (Harris and Maricq 2000). In general, combustion engines produce mean aerosol size distributions dominated by the Aitken mode. Smaller size distributions can be attributed to more efficient combustion sources that are observed at shorter distances between the source and the measurement site (Lighty et al. 2000).

In Figure 7 we compare the measured size distributions from the UHSAS at C1 and S1 in the summer and winter. During the summer, the size distributions were similar in number concentration and the mean mode $D_{p}$ of $150 \mathrm{~nm}$ for the size ranges measured at both sites. A bimodal size distribution was evident, but the peak of the smaller mode was not able to be determined with the measurements here. Despite not being able to size particles with $D_{p}<70 \mathrm{~nm}$,the combined analysis presented in Section 4.3 enabled us to conclude that more than half of the $N_{\text {tot }}$ observed at C1 and S1 were due to particles with $D_{p}<70 \mathrm{~nm}$. The main difference observed between the measured size distributions at C1 and S1 in the summer was that there were $11 \%$ more particles from $70 \mathrm{~nm}$ to $150 \mathrm{~nm}$ at C1 than S1 (Figure 7a).

In the winter, the bimodal structure was less evident at C1 and S1 (Figure 7b). The main difference between C1 and S1 was that C1 had 38\% more aerosol with $D_{p}$ of $70 \mathrm{~nm}$ to $150 \mathrm{~nm}$ than S1. This difference was $\sim$ a factor of four times larger than what was observed in the summer. The peak of the size distribution was also shifted to slightly smaller sizes than $150 \mathrm{~nm}$ at C1 than S1. This could have been 
due to the presence of more local sources with aerosols $<100 \mathrm{~nm}$ at C1 than S1 in the winter and/or to different meteorological conditions than were observed in the summer. This difference in season was in agreement with Figure 6 (Section 4.3) where a higher difference between $N_{\text {tot }}$ was observed between C1 and $\mathrm{S} 1$ in the winter than in the summer.

During summer and winter, C1 had more aerosol than S1 for $D_{p}<150 \mathrm{~nm}$ that could be counted by the UHSAS. This was likely due to the closer proximity of C1 to the airport and the road to Santa Cruz. While the difference between the size distributions measured at C1 and S1 in the summer was minimal for $D_{p}>70 \mathrm{~nm}$, we expect the difference would be more evident if sizing were available for $D_{p}<70 \mathrm{~nm}$ at ENA. We base this statement on the comparison of $N_{\text {tot }}$ and $N_{U H S A S}$ in the previous section. For this reason, we combined the information from the two instruments to further understand the Aitken mode aerosol in the next section.
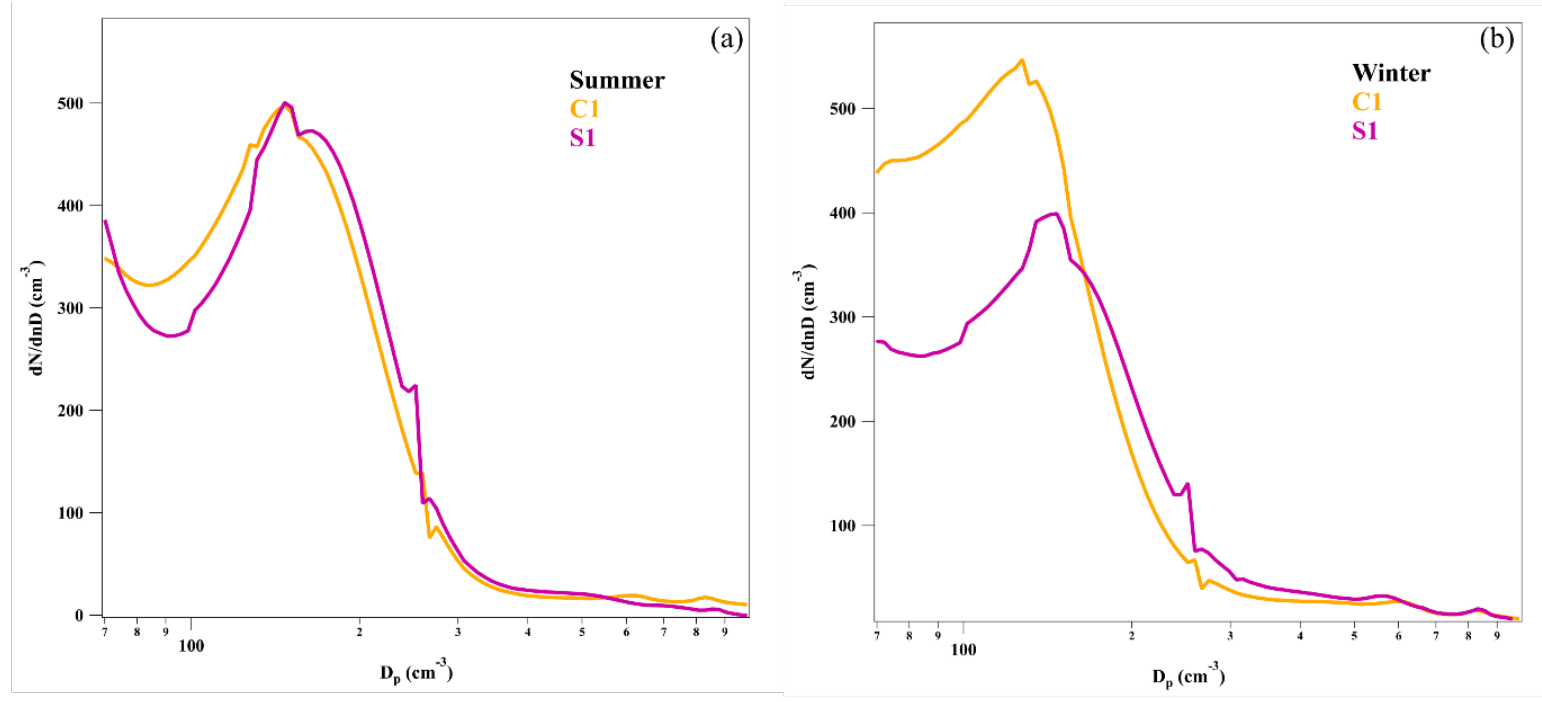

Figure 7. Submicron aerosol size distributions at C1 (orange) and S1 (pink) during summer (a) and winter (b).

\subsubsection{Submicron Aerosol Modes}

Number concentrations from three aerosol modes that we defined in Section 3.1 are presented in Figure 8 from C1 and S1 in summer and winter. The smallest mode number concentration, $N_{A t}$, represents the size range most likely impacted by nearby combustion sources as discussed in the Section 4.4.1. $N_{A c}$ is expected to include some of these particles as well, especially for the less efficient combustion sources and operational modes, such as are produced by diesel engines and even more so for wood-burning sources not discussed here. The third and largest mode number concentration, $N_{L A}$, is not expected to be significantly impacted by nearby combustion aerosol sources. However, $N_{L A}$ is presented since it includes natural aerosol sources such as sea spray (Burrows et al. 2014, Quinn et al. 2015) and secondary organic aerosol (Jimenez et al. 2009, Shrivastava et al. 2019) that can also be formed in association with combustion sources.

For the three submicron size modes analyzed at C1 and S1, $N_{A t}$ had the largest median and mean number concentrations, equating to $69 \%$ of the median and $78 \%$ of the mean for the total submicron aerosol 
concentrations, $N_{\text {tot }}$, when averaged from the different sites and seasons. $N_{A t}$ also had the highest deviation between the mean and median of the three size modes. This result was observed during the summer and winter. Mean $N_{A t}$ were $540 \mathrm{~cm}^{-3}$ (C1) and $330 \mathrm{~cm}^{-3}$ (S1) in the summer (Figure 8a). In the winter at C1, the mean $N_{A t}$ was $800 \mathrm{~cm}^{-3}$, which was $48 \%$ higher than what was observed in the summer (Figure $8 \mathrm{~b}$ ). Median $N_{A t}$ at C1 were relatively constant at $245 \mathrm{~cm}^{-3}$ in the summer and $258 \mathrm{~cm}^{-3}$ in the winter. Median $N_{A t}$ at $\mathrm{S} 1$ were $78 \%$ of C1 with $190 \mathrm{~cm}^{-3}$ measured in the summer. While median $N_{A t}$ were relatively constant for the data shown here at both seasons and sites, mean $N_{A t}$ varied with site and season.

The higher observed mean $N_{A t}$ at $\mathrm{C} 1$ during the winter indicated that the influence of nearby aerosol sources was likely to be larger in the winter than in the summer at C1. This result is supported by the earlier results from $N_{\text {tot }}$ (Section 4.3: Figure 6a,c) and the submicron size distributions (Section 4.4.1: Figure $7 \mathrm{~b}$ ). The reason for the higher fraction of $N_{A t}$ observed in the winter at C1 could have been due to additional seasonal sources that were not attributed here, such as the burning of wood or other fuels to heat homes, more sea spray aerosol due to higher wind speeds, etc. For example, higher $N_{A t}$ from the known sources discussed in Section 4.4.1 might also be observed due to different winter meteorological conditions such as lower boundary height, higher wind speeds, etc.
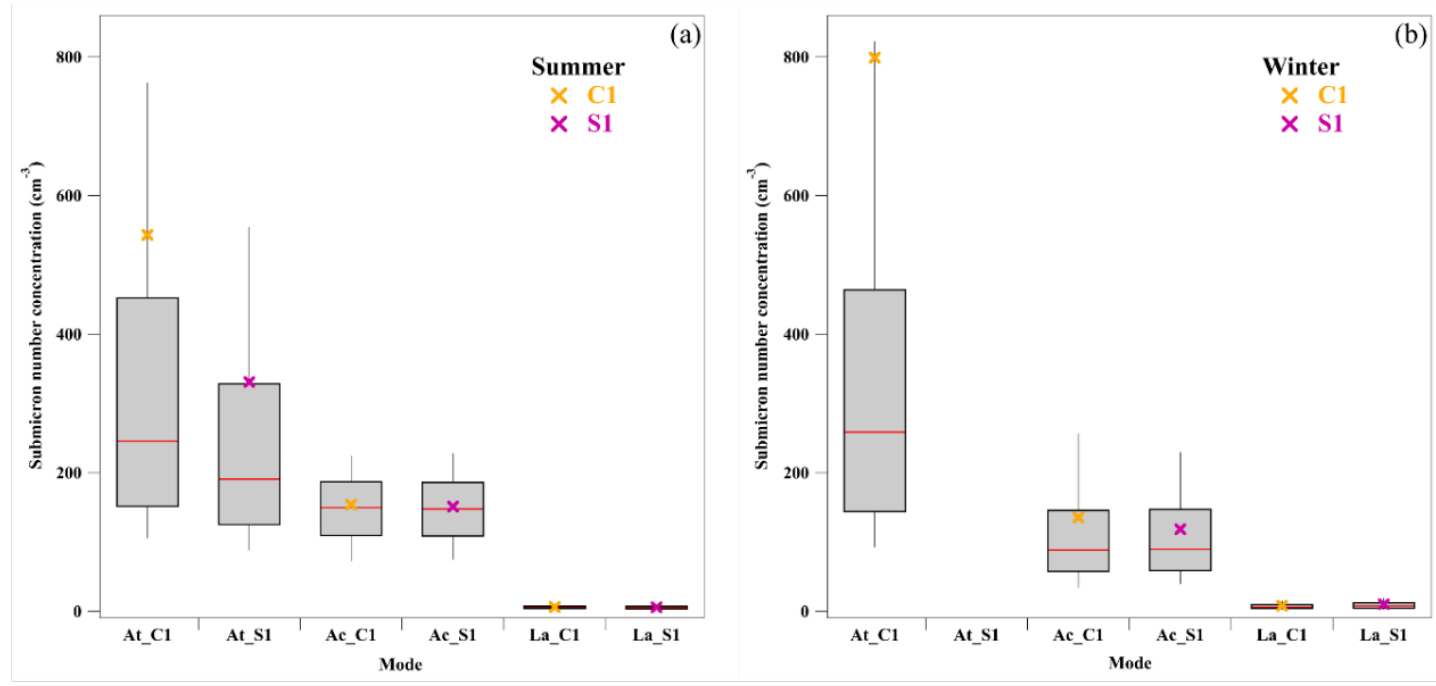

Figure 8. Box-and-whisker plot of $N_{A t}, N_{A c}$ and $N_{L A}$ at C1 (orange) and S1 (pink) in the summer (a) and winter (b). Mean (x) and median (red line). Box bottom at 25\%, box top at 75\%, whisker bottom at $10 \%$, and whisker top at $90 \%$. $N_{A t}$ not available at S1 in winter.

Mean and median $N_{A c}$ were lower than $N_{A t}$ during summer and winter at C1 and S1, yet still represented a significant fraction of $N_{\text {tot. }}$ In the summer, C1 and S1 $N_{A c}$ had similar mean and median values, indicating low variability in the data. Mean $N_{A c}$ observed were $154 \mathrm{~cm}^{-3}$ (C1) and $151 \mathrm{~cm}^{-3}$ (S1). Median $N_{A c}$ were $149 \mathrm{~cm}^{-3}$ (C1) and $148 \mathrm{~cm}^{-3}$ (S1). The similar values between the mean and median $N_{A c}$ at both sites indicated that the mode was not largely affected by high-concentration aerosol events, typical of local emissions. In the winter, mean $N_{A c}$ were $13 \%$ (C1) and 22\% (S1) lower than mean $N_{A c}$ in the summer. Mean $N_{A c}$ were $135 \mathrm{~cm}^{-3}$ (C1) and $118 \mathrm{~cm}^{-3}$ (S1). Median $N_{A c}$ were $88 \mathrm{~cm}^{-3}$ (C1) and $89 \mathrm{~cm}^{-3}$ (S1). Overall, $N_{A c}$ at C1 and S1 were more similar than $N_{A t}$ in summer and winter. However, there was higher variability between the mean and median $N_{A c}$ observed during the winter that was not observed in the summer. 
$N_{L A}$ did not represent a significant fraction to $N_{\text {tot }}$ at ENA for the data presented here. Mean $N_{L A}$ during the summer were $6 \mathrm{~cm}^{-3}$ at C1 and S1. Similar $N_{L A}$ were observed in the winter at $8 \mathrm{~cm}^{-3}$ (C1) and $10 \mathrm{~cm}^{-3}$ (S1). While $N_{L A}$ is important in regard to mass concentrations, scattering properties, and their ability to function as cloud condensation nuclei, which are all properties measured by the AOS (Uin et al. 2019), $N_{L A}$ are not generally attributed to local combustion aerosol sources, which was the focus here. Contributions and impacts to $N_{L A}$ due to sea spray aerosol were beyond the scope of this work.

\subsubsection{Variability with Wind Direction}

Mean $N_{A t}$ had the highest variability of all modes as discussed above. $N_{A t}$ and $N_{A c}$ have a larger observed variability in the winter than in the summer. For these reasons we evaluated the dominant submicron size modes as a function of wind direction to assess the variability in association with the direction of the local aerosol identified in Section 4.2. $N_{A t}$ and $N_{A c}$ are plotted in Figure 9 at C1 and S1 during the summer and winter.

$N_{A t}$ at C1 (Figure 9a) had the highest deviations between the mean and median when the wind was coming from the west (mean: $1,007 \mathrm{~cm}^{-3}$, median: $185 \mathrm{~cm}^{-3}$ ) and northwest (mean: $623 \mathrm{~cm}^{-3}$, median: $148 \mathrm{~cm}^{-3}$ ) in the summer. $N_{A t}$ at $\mathrm{C} 1$ from the west and northwest are associated with the direction of the airport runway. Aircraft produce submicron aerosol of different mean $D_{p}$ during different modes of operation. Distinct aerosol size distributions centered at $\sim 90 \mathrm{~nm}$ have been observed from nearby aircraft during landing and take-off, while a sub-30-nm mode has been observed to be prevalent during periods when aircraft are idling on the ground (Herndon et al. 2005). While we were not able to resolve these differences in the ENA data set due to the lack of size information for $D_{p}<70 \mathrm{~nm}$, we were able to confirm that the largest variability was observed in the smallest mode of particles shown here, $N_{A t}$, when the wind is coming from the directions associated with the airport and its operation. $N_{A t}$ from the direction of the road to the airport, east to south, at C1 was not observed to have significantly higher variability that the other directions.

$N_{A t}$ at S1 had less variability between the mean and median when averaged over all wind directions in comparison to C1 (Figures 8b, 9b) in the summer. The highest variability in the data at S1 was associated with wind directions from the east (mean: $507 \mathrm{~cm}^{-3}$, median: $294 \mathrm{~cm}^{-3}$ ) and southeast (mean: $498 \mathrm{~cm}^{-3}$, median: $326 \mathrm{~cm}^{-3}$ ). The road and pasture were to the east and the airport runway, terminal, and parking lot were to the southeast of S1.

Winter $N_{A t}$ at C1, not shown, exhibited a similar trend in regard to the summer data with the highest $N_{A t}$ coming from the west. $N_{A t}$ from the west had the highest mean of all the wind directions at 1,650 $\mathrm{cm}^{-3}$ with a corresponding median an order of magnitude lower at $170 \mathrm{~cm}^{-3}$. The deviation between the median and the mean was also the greatest from the west, approximately a factor of two times greater than what was observed in the summer. The deviation in the mean and median when the wind was coming from the northwest was smaller than what was observed in the summer at C1. $N_{A t}$ was not available at S1 in the winter for comparison, although we expect S1 would have had less variability than what was observed at $\mathrm{C} 1$ in the winter. 


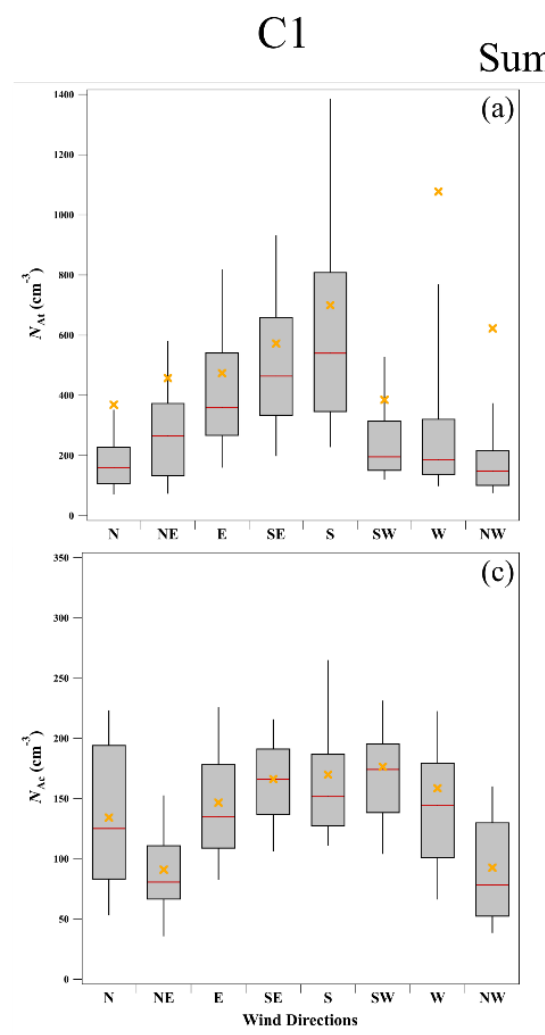

S1

(a)

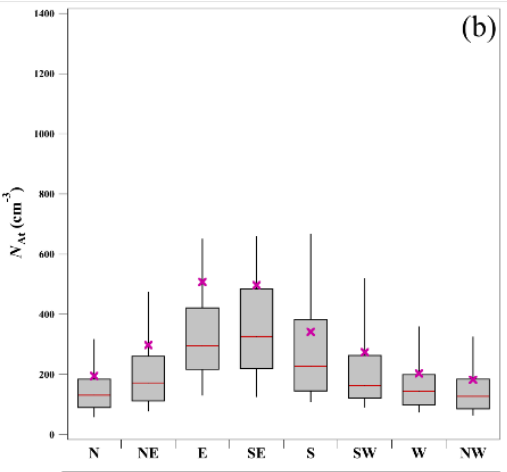

c)

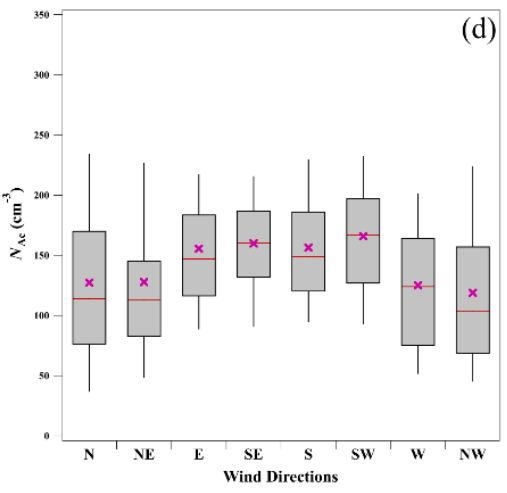

Winter
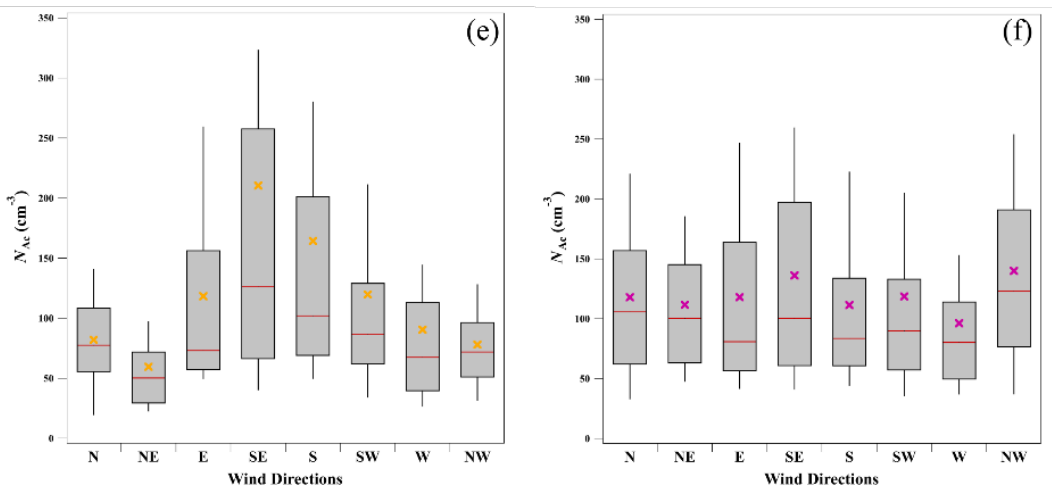

Figure 9. Summer $N_{A t}$ at (a) C1 and (b) S1, $N_{A c}$ at (c) C1 and (d) S1, and winter $N_{A c}$ at (e) C1 and (f) S1 plotted as a function of wind direction. Mean (x) and median (red line). Box bottom at 25\%, box top at $75 \%$, whisker bottom at $10 \%$, and whisker top at $90 \%$.

As was observed in Figure 8, $N_{A c}$ represented a smaller fraction of the total submicron aerosol at C1 and S1 with a lower variability between the median and mean $N_{A c}$. Mean and median $N_{A c}$ in Figure 9c,d had a low variability across all wind directions at $\mathrm{C} 1$ and S1 in the summer. This is in contrast to what was observed for $N_{A t}$ during the same period. Mean $N_{A c}$ were between 92 and $170 \mathrm{~cm}^{-3}$ at C1, and the median $N_{A c}$ were between 78 and $174 \mathrm{~cm}^{-3}$. Mean $N_{A c}$ were between $118 \mathrm{~cm}^{-3}$ and $165 \mathrm{~cm}^{-3}$ at $\mathrm{S} 1$ in the summer (Figure 9d). The median $N_{A c}$ were between $103 \mathrm{~cm}^{-3}$ and $166 \mathrm{~cm}^{-3}$.

The largest variability of $N_{A c}$ at C1 was observed in the winter when the wind was from the southeast (mean: $210 \mathrm{~cm}^{-3}$, median: $126 \mathrm{~cm}^{-3}$ ) and south (mean: $164 \mathrm{~cm}^{-3}$, median: $102 \mathrm{~cm}^{-3}$ ) as shown in Figure 9e. 
However, this variability was less than what was observed for $N_{A t}$ as a function of wind direction in the winter. Winter $N_{A c}$ at S1 (Figure 9f) had more variability between the median and mean $N_{A c}$ than what was observed in the summer $N_{A c}$. It was still significantly less than what was observed in the $N_{A t}$ in the summer as was observed at C1. The largest variability in $N_{A c}$ at $\mathrm{S} 1$ in the winter was observed when the wind was coming from the east (mean: $123 \mathrm{~cm}^{-3}$, median: $80 \mathrm{~cm}^{-3}$ ) and southeast (mean: $140 \mathrm{~cm}^{-3}$, median: $96 \mathrm{~cm}^{-3}$ ). S1 data when compared to $\mathrm{C} 1$ have less variability across all wind directions and seasons, similar to what was observed when comparing $N_{A t}$ at $\mathrm{C} 1$ and $\mathrm{S} 1$.

In summary for the data shown here, $N_{A t}$ exhibited the highest variability represented as a high bias of the mean versus the median of all the submicron modes presented at C1 and S1. The highest bias in the mean values in comparison to the medians was associated with the direction of airport operations at C1 (north and northwest) and S1 (east, southeast and south). At ENA the high $N_{A t}$ variability was most likely due to local combustion sources based on the size and the wind directions during which they were observed. This conclusion is supported the fact that combustion sources are known to produce high concentrations of small-mode particles with $D_{p}<200 \mathrm{~nm}$. The high variability observed at ENA was mostly confined to the $N_{A t}$, although was also observed in $N_{A c}$ during the winter. The main sources of $N_{A c}$ at ENA have been largely attributed to the entrainment of aerosol from within the free troposphere and the growth of $N_{A t}$ (Zheng et al. 2018). As such, the variability observed here within $N_{A c}$ in the winter likely included these processes, local aerosol sources, and atmospheric processes that were not observed in the summer. Chemical and optical property measurements collected by the AOS should be used in the future to further validate the aerosol sources associated with the variability observed here in summer and winter at ENA.

\subsection{High-Time-Resolution Data}

Time series of $N_{\text {tot }}$ at C1 and S1 indicated that both locations periodically sampled high concentrations of particles over short time periods ( $<4$ minutes). High aerosol signals such as these are typically the result of local sources due to their high concentrations and short durations, which would become less evident at greater distances from the source. Since aircraft idling, taxiing, take-off, and landing are all potential times when high aerosol number concentrations could be sampled at C1 and S1, we used the Graciosa airport flight logs and the AOS camera observations to interpret high-time-resolution $N_{\text {tot }}$ data at ENA.

In Figure 10 we present two four-day periods sampled at C1 and S1 during the summer. $N_{\text {tot }}>25,000 \mathrm{~cm}^{3}$ were observed on a daily basis at C1 in the raw one-second data (Figure 10a). Lower $N_{\text {tot }}$ daily maximum concentrations $>11,000 \mathrm{~cm}^{-3}$ were observed at S1. Winter $N_{\text {tot }}$ daily maximums at C1 were $>20,000 \mathrm{~cm}^{-3}$ with maximum concentrations occasionally $\sim 80,000 \mathrm{~cm}^{-3}$. Figure $10 \mathrm{~b}$ shows a period when the overall trend was the opposite of Figure 10a. Higher $N_{\text {tot }}$ were observed at S1 in comparison to C1. While this period did not represent the overall trend in $N_{\text {tot }}$ between C1 and S1 time series data, it was included to show that $\mathrm{C} 1$ and S1 both observed $N_{\text {tot }}$ maximums at different times and that both sites are impacted by high-concentration aerosol events in high time resolution. 

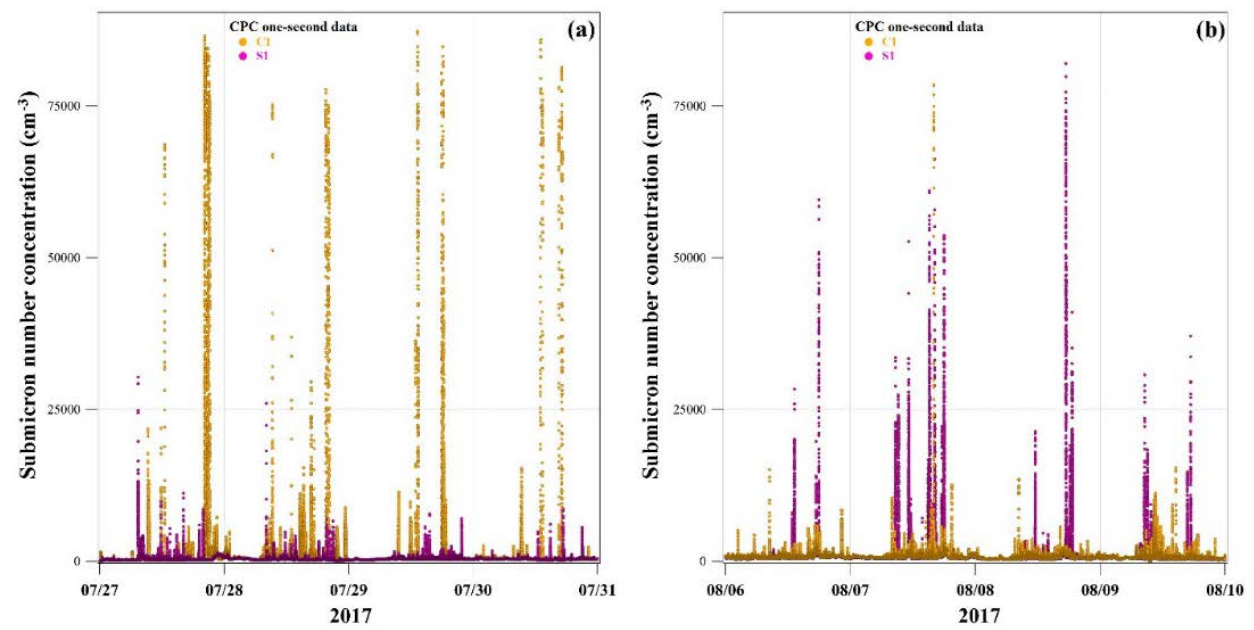

Figure 10. Sample time periods of one-second $N_{\text {tot }}$ at C1 (orange) and S1 (pink) during the summer during a (a) typical day and when (b) S1 sampled higher $N_{\text {tot }}$ aerosol events than C1.

Graciosa airport on average hosted two flights a day; the first was typically in the late morning/early afternoon and the second was in the late afternoon. The airport time tables for 2017 and 2018 reported that planes landed and took off from Graciosa Island during three distinct time periods throughout the day: 17\% of the planes arrived at Graciosa airport between 8:30 and 11:00 UTC, 26\% between 13:00 and 15:00 UTC, 56\% between 17:00 and 20:00 UTC. Taking into account the wind direction, planes typically landed from the east and took off from the west. We confirmed that during the summer $97 \%$ of the flights occurred in this direction by analyzing the daily videos from the AOS cameras at C1. However, due to the runway's limited length, planes often used the full length of the runway, which could be observed in $N_{\text {tot }}$ at C1 and S1. Such occurrences affected $N_{\text {tot }}$ at C1 the most when the wind direction was between northeast and west, and S1 when the wind came from the east to southwest.

To further understand the potential influence of the airport operations on $N_{\text {tot }}$ at C1 and S1, we examined a one-day period in detail. In Figure 11 we present C1 and S1 one-minute time resolution $N_{\text {tot }}$ on August 3, 2017. $N_{\text {tot }}$ at S1 was largely unaffected by the short-duration, high-concentration aerosol events as $N_{\text {tot }}$ never was $>1,000 \mathrm{~cm}^{-3}$. While this was only a one-day period and was by no means representative of daily $N_{\text {tot }}$, we include it as an example of the complexity within $N_{\text {tot }}$ observed at ENA.

Throughout the day, abrupt changes in wind direction were observed. Winds from the south, southwest, and west dominated until 17:58 UTC. Starting at 18:00 UTC, the dominant wind directions were northwest, north, and east. Analysis of the video from the AOS camera mounted at C1 showed that diesel-engine trucks were present on the runway from 09:07 UTC to 09:27 UTC for the daily maintenance of the runway. Twice during the afternoon, from 13:42 to 15:02 UTC and 18:46 to 19:51 UTC, the aircraft was viewed by the AOS cameras to be idling near the airport terminal building. The time when the trucks were observed on the runway is highlighted in yellow, and the times when the aircraft was parked near the terminal is shown in grey in Figure 11. During the first part of the day when the wind directions were from the south and west, $N_{\text {tot }}>1,000 \mathrm{~cm}^{-3}$ at C1 numerous times. In Section 4.2 we identified these directions for $\mathrm{C} 1$ as being related to the airport terminal, the airport parking lot, and the road to the airport. Later in the day when the winds were coming from the northwest to east in the direction of the runway at C1, $N_{\text {tot }}<1,000 \mathrm{~cm}^{-3}$ at C1 similar to $N_{\text {tot }}$ at $\mathrm{S} 1$. 


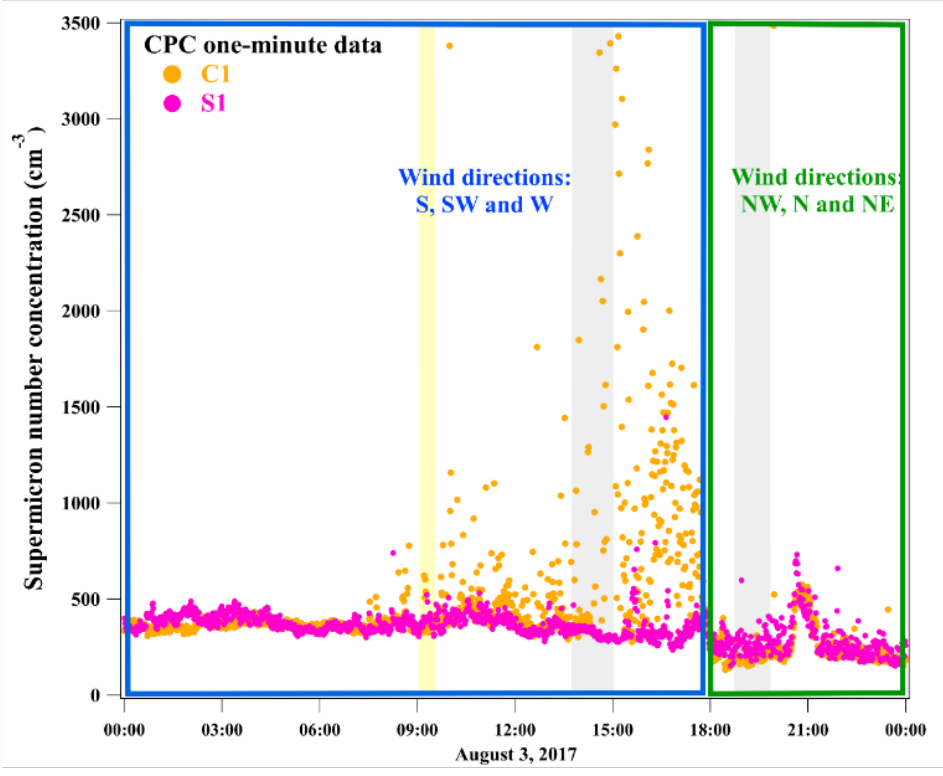

Figure 11. $N_{\text {tot }}$ at C1 (orange) and S1 (pink) on August 3, 2017. Yellow and grey periods indicate when the AOS cameras observed trucks on the runway (yellow) and aircraft near the terminal building (grey). Blue and green boxes indicate the dominant wind directions.

The high- $N_{\text {tot }}$ events observed at C1 and S1 were associated with the airport activities and increased road traffic that generally occurred before the arrival and after the departure of the aircraft based here on visual observations, airport flight logs, and wind degree direction analysis. The aircraft and vehicle impacts were observed by sharp peaks occurring on timescales on the order of minutes when $N_{\text {tot }}$ was often an order of magnitude above the baseline signal. In contrast, the airport operations tended to cause periods of elevated $N_{\text {tot }}$ that occurred over longer timescales on the order of a few hours. Therefore, the impact of the airport, its operation, and associated traffic on the AOS data at ENA could not be constrained to the arrival and departure times of the aircraft since it was also impacted by airport operations that occurred throughout the day and the wind direction in relation to C1 and S1. For these reasons, the periods when the aircraft was present on the ground should not be used alone to determine when ENA was impacted by the local airport and its operation.

\subsection{Diurnal Profile}

While the influence of the airport operations might not be readily apparent from the short-duration high $N_{\text {tot }}$ observed at C1 and S1, further information constraining this influence can be obtained by looking at the diurnal cycle of mean and median $N_{\text {tot }}$ at C1 (Figure 12). The three hourly periods with highest mean $N_{\text {tot }}$ were observed during 9:00 to 10:00 UTC at $916 \mathrm{~cm}^{-3}, 13: 00$ to 14:00 UTC at $860 \mathrm{~cm}^{-3}$, and 17:00 to 18:00 UTC at $1,595 \mathrm{~cm}^{-3}$. These three elevated-mean- $N_{\text {tot }}$ periods occurred during the three times when the airport hosted flights. These periods were identified using the airport flight logs and are shown as the black boxes in Figure 12. The highest mean $N_{\text {tot }}$ was observed during the third time period identified by the airport to host, on average, half of the daily flights, while the two earlier time periods were only associated with $\sim 25 \%$ of the flights each. Two other high-mean- $N_{\text {tot }}$ periods were observed during the 
diurnal profile at C1. Mean $N_{\text {tot }}$ were $615 \mathrm{~cm}^{-3}$ from 7:00 to 8:00 UTC, that occurred during a similar time that the AOS cameras observed the daily maintenance of the runway with diesel trucks from 7:45 and 8:30 UTC. The second period from 20:00 to 21:00 with mean $N_{\text {tot }}>800 \mathrm{~cm}^{-3}$ was not able to be attributed to aerosol sources at this time.

The diurnal variation observed in the mean $N_{\text {tot }}$ at C1 in summer was not observed in the median $N_{\text {tot }}$. Hourly averaged medians exhibited low variability throughout the day. A maximum of $506 \mathrm{~cm}^{-3}$ was observed in the late afternoon between 17:00 and 18:00 UTC, and a minimum of $380 \mathrm{~cm}^{-3}$ was observed during the night between 23:00 and 24:00 UTC.

At ENA, the periods with the largest deviation between the median and mean $N_{\text {tot }}$ were during the three periods when most of the flights occurred at the airport. A diurnal variation was observed in the mean $N_{\text {tot, }}$ yet was not statistically relevant for the median $N_{\text {tot }}$ of the same data at C1 and S1. While not shown here, $\mathrm{S} 1$ had a similar trend in the diurnal profile to what was observed at $\mathrm{C} 1$ in the summer. The main difference was that the mean $N_{\text {tot }}$ were all $<1,000 \mathrm{~cm}^{-3}$. Winter data at $\mathrm{C} 1$ also had the highest mean $N_{\text {tot }}$ and their deviations from the medians during the hours of airport operations as shown here for the summer. We use the information from the diurnal profiles at ENA to validate the statement that the airport operations and associated activities were the largest sources of high-concentration $N_{\text {tot }}$ observed at ENA.

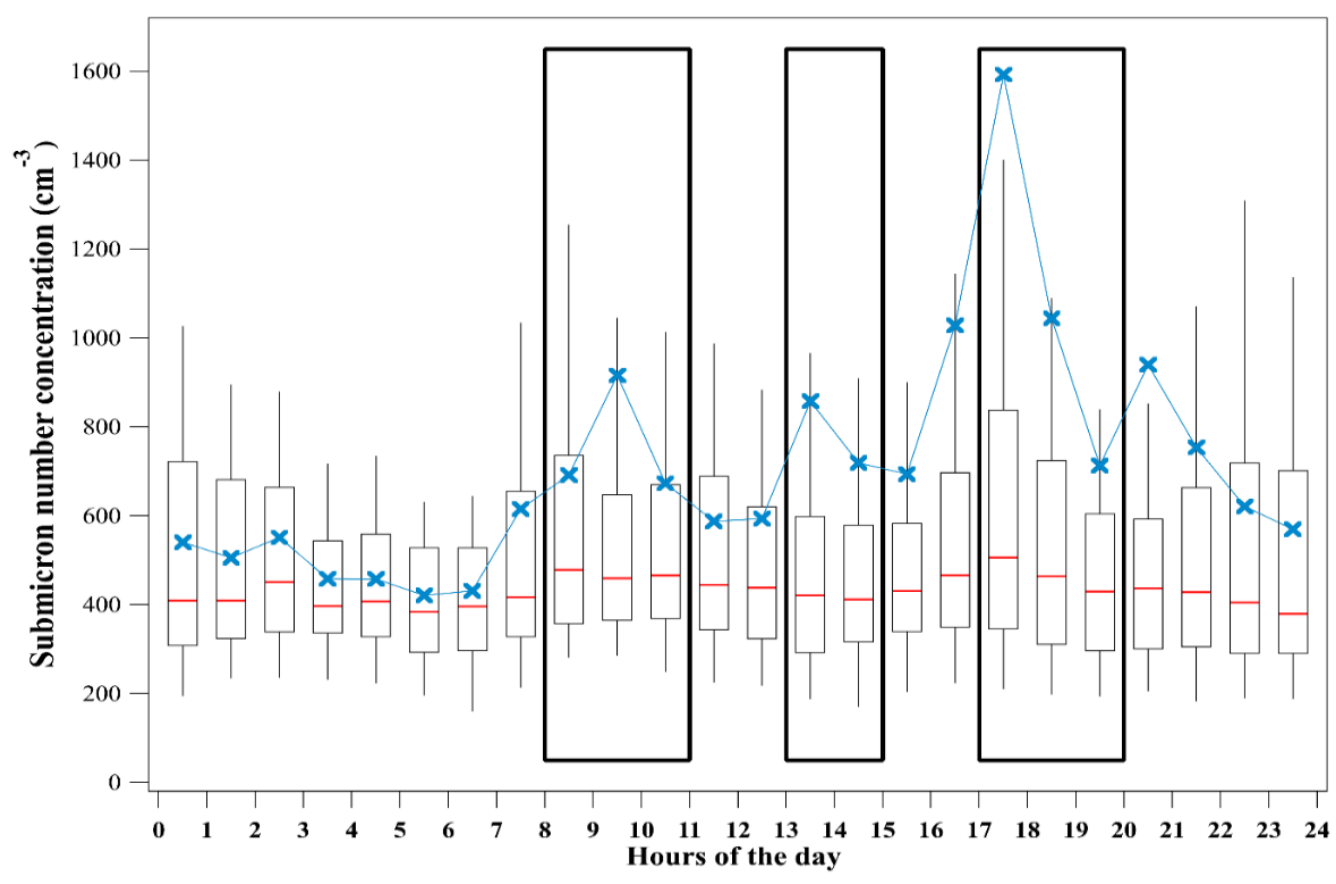

Figure 12. Box-and-whisker diurnal profile of $N_{\text {tot }}$ at C1 during summer. The three daily time periods when aircraft flight logs indicate aircraft were present at the Graciosa airport in bold black boxes. $N_{\text {tot }}$ mean (blue x) and median (red line). Box bottom at $25 \%$, box top at $75 \%$, whisker bottom at $10 \%$, and whisker top at $90 \%$. 


\subsection{High-Number-Concentration ENA Aerosol Mask}

\subsubsection{Algorithm Optimization}

Before applying a mathematical algorithm to mask high-number-concentration events in high-time-resolution data, optimal input parameters were determined. We conducted a sensitivity test to select the best $\alpha$ parameter and thresholding method to apply the algorithm to the one-minute-resolution $N_{\text {tot }}$ data at ENA. We conducted the test using $N_{\text {tot }}$ from C1 and S1 in the summer. Table 5 shows the combination of $\alpha$ values and thresholding methods that were tested.

Table 5. Standard deviation algorithm input parameters tested at C1 and S1 in the summer.

\begin{tabular}{c|c|c}
\hline \multicolumn{2}{c|}{ Random Walk (RW) Threshold } & Two-point (TP) Threshold \\
\hline$\alpha=1$ & $\alpha 1-\mathrm{RW}$ & $\alpha 1-\mathrm{TP}$ \\
$\alpha=3$ & $\alpha 3-\mathrm{RW}$ & $\alpha 3-\mathrm{TP}$ \\
\hline
\end{tabular}

Previous studies used the random walking threshold with aerosol data. Drewnick et al. (2012) used $\alpha=3$ to remove sharp and short peaks that lasted up to few seconds in $N_{\text {tot }}$ from the CPC and gas-phase CO measurements from a mobile aerosol research laboratory. The authors found that the application of the a3-RW parameterization only worked well when the density of the high-concentration events was low. Similarly, El Yazidi et al. (2018) used $\alpha 1-\mathrm{RW}$ with gas-phase $\mathrm{CO}_{2}$ and $\mathrm{CH}_{4}$ measurements at four different stations in Europe that had high-concentration events over periods of a few minutes. They showed that the $\alpha 1-\mathrm{RW}$ parameterization was able to detect $\sim 96 \%$ of the events that were visually identified by the station manager. Therefore, we began to develop an algorithm at ENA by testing the two $\alpha$ values with the RW threshold that were used in these two studies.

We present in Figure 13 the results from the application of the algorithm over the same 24-hour period that we analyzed previously in Section 4.5, Figure 11. The first two parameterizations selected, $\alpha 1-\mathrm{RW}$ and $\alpha 3-\mathrm{RW}$, were able to identify the first data points of a high- $N_{\text {tot }}$ event, but were not able to identify events that occurred over extended periods, as is shown in Figure 13a for the application of $\alpha 3-\mathrm{RW}$ at C1. While $\alpha 1-\mathrm{RW}$ was not included in the figure for simplicity, similar results were produced from this parameterization. Next, we constrained the threshold more by applying the TP threshold with the same $\alpha$ values. The $\alpha 1$-TP parameterization was the only parameterization able to identify the longer-duration events that lasted from minutes to hours, as were experienced due to airport operations as shown in Figure 13b. Results from $\alpha 3$-TP were not included in the figure as the combination of the relaxed $\alpha$ and constrained TP threshold parameters, $\alpha 3$-TP, yielded similar results to the RW threshold parameterizations tested previously. The $\alpha 3$-TP parameterization was not able to identify the longer-duration, high- $N_{\text {tot }}$ events.

In conclusion, when high- $N_{\text {tot }}$ events had durations on the order of hours, the rate of change in the signal between the adjacent points was not high enough to be identified by either the RW threshold or the higher $\alpha=3$ parameter combinations tested at $\mathrm{C} 1$. We also were able to conclude that at ENA one-minute $N_{\text {tot }}$ had sufficient time resolution to mask the high- $N_{\text {tot }}$ events to apply the algorithm at ENA. Application to the higher-time-resolution, one-second $N_{\text {tot }}$ data was therefore not necessary based on the validation of the ENA algorithm presented here. 

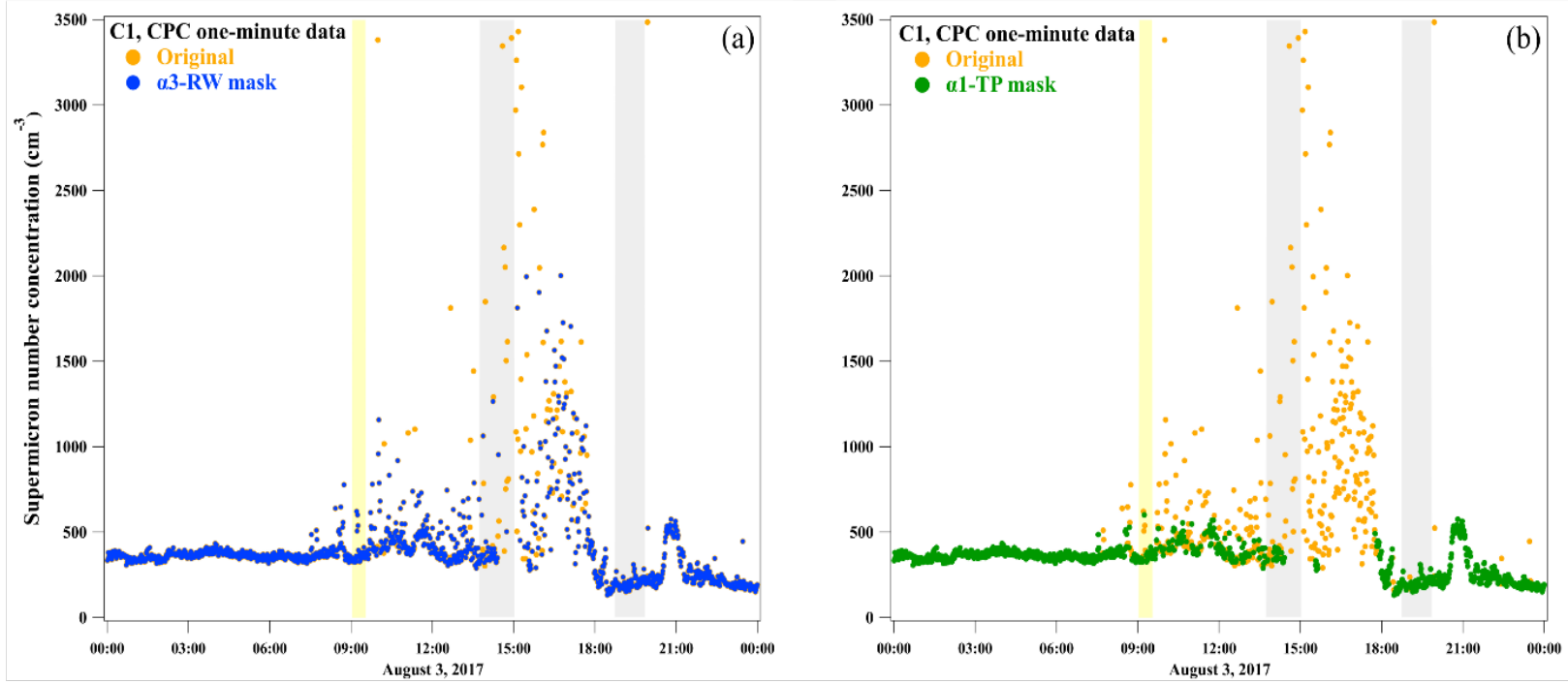

Figure 13. Original (orange points) and masked $N_{\text {tot }}$ at C1 using (a) $\alpha 3-\mathrm{RW}$ (blue points) and (b) $\alpha 1-\mathrm{TP}$ (green points) input parameterizations over a 24-hour period on 8/3/2017. Yellow and grey boxes were periods when the AOS cameras at C1 detected planes (grey) and trucks (yellow) on the runway.

Similar results were obtained when we tested the four parameterizations of the algorithm on $N_{\text {tot }}$ at S1, not shown here. As we observed at $\mathrm{C} 1$, the tightest combination of parameters, $\alpha 1-\mathrm{TP}$, was able to most accurately identify all of the high- $N_{\text {tot }}$ events of all the parameterizations tested here. The higher $\alpha$ values and the random walk threshold relaxed the algorithm such that the number of data points identified was likely to underestimate the number and duration of high- $N_{\text {tot }}$ events observed at ENA. Therefore, we used the $\alpha 1$-TP parameterization to create an aerosol mask at ENA using $N_{\text {tot. }}$

\subsubsection{Validation}

In this section we use the ENA Aerosol Mask (ENA-AM) to define a regional baseline for $N_{\text {tot }}$ at ENA. The scatter plot in Figure 14 shows $N_{\text {tot }}$ at C1 and S1 during the summer for the original and data masked with ENA-AM. Due to the diverse high- $N_{\text {tot }}$ events and local sources at ENA, the linear regression R-squared $\left(\mathrm{R}^{2}\right)$ value of the original $N_{\text {tot }}$ between the two sites (black dots) was minimal $\left(\mathrm{R}^{2}=0.03\right)$. After applying ENA-AM to both data sets (green dots), the linear regression significantly improved, generating an $\mathrm{R}^{2}=0.87$ with a slope $=0.84$ when the data was fit through zero. With the application of ENA-AM at $\mathrm{C} 1$ and S1, a regional baseline was identified for the $N_{\text {tot }}$ one-minute data that agreed within measurement uncertainties. The variability in the original $N_{\text {tot }}$ that was removed with the ENA-AM was attributed to the high- $N_{\text {tot }}$ events associated with local sources at ENA. The reasons for the on-average $16 \%$ higher $N_{\text {tot }}$ baseline at C1 after applying ENA-AM was not investigated here, but should be in the future. 


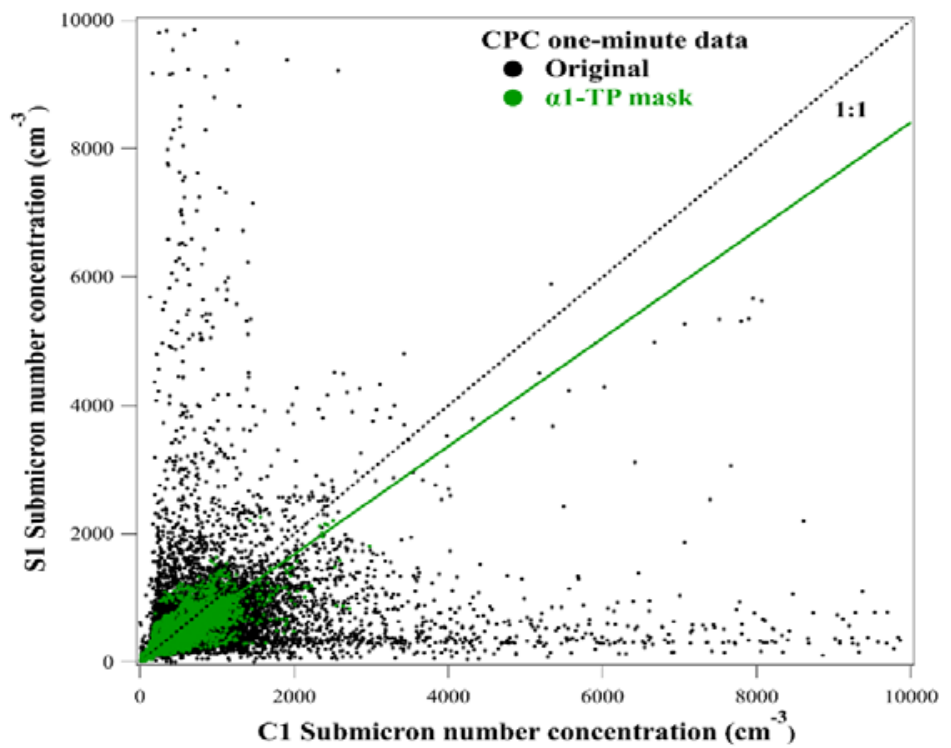

Figure 14. Scatter plot of one-minute $N_{\text {tot }}$ at C1 and S1. Original (black) and ENA-AM masked (green).

We evaluated the ability of ENA-AM to mask short-lived high- $N_{\text {tot }}$ events during periods when ENA sampled long-range transported aerosol. Periods with elevated aerosol concentrations due to long-range-transported continental sources occurred at ENA for durations on the order of days to weeks. Through the analysis of back trajectories and aerosol optical properties, we identified an episode of transported aerosol from Central Africa and the Canary Islands from January 7 to 12, 2017 (Figure 15). For several days during this time, $N_{\text {tot }}$ at ENA remained $>700 \mathrm{~cm}^{-3}$, likely due to a mixture of mineral dust and black carbon from biomass burning sources (Logan et al. 2014) as have been observed from other continental sources at ENA (Zheng et al. 2019). After applying ENA-AM to $N_{\text {tot }}$ at C1, we observed that the majority of the data associated with the multi-day event were retained as baseline $N_{\text {tot }}$ while the short-duration, high- $N_{\text {tot }}$ events previously attributed to local sources were removed (Figure 15). The results from this case study validated the application of ENA-AM to one-minute $N_{\text {tot }}$ during a period when multi-day, entrained long-range transported aerosol was sampled at ENA.

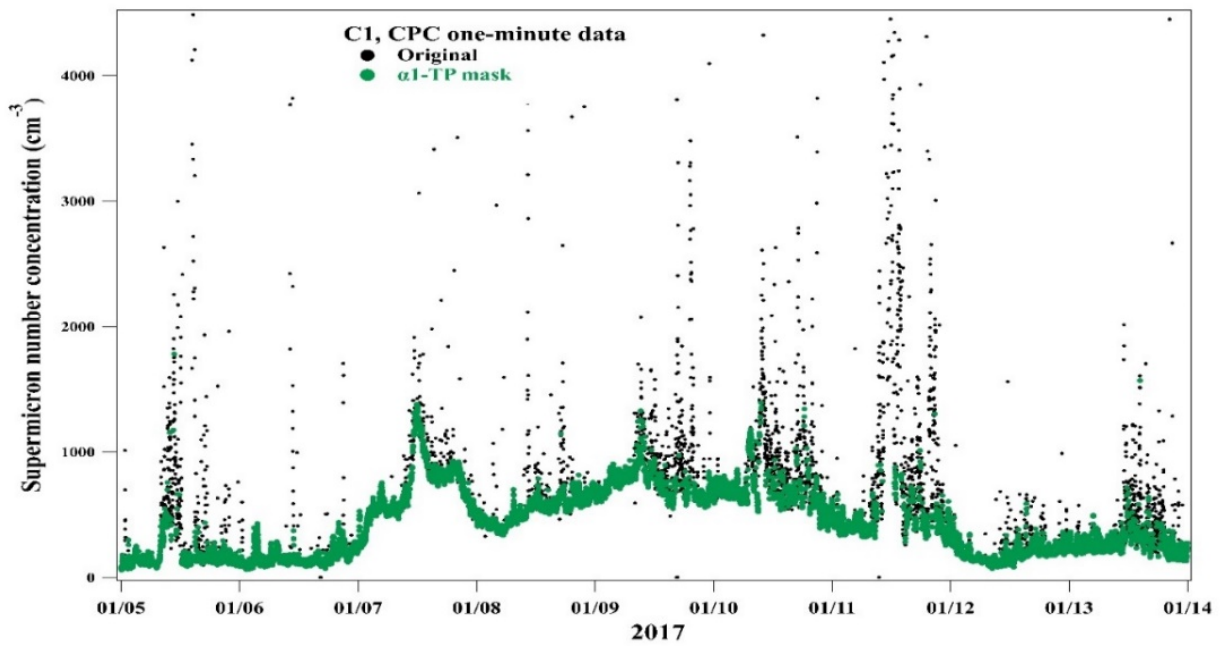

Figure 15. $N_{\text {tot }}$ at $\mathrm{C} 1$ during an episode of long-range transport of continental air masses, original (black) and masked (orange) CPC data using ENA-AM. 


\subsection{Conclusions from ENA and Future Work}

High-number-concentration aerosol events were observed to originate from a range of wind directions at ENA. The predominant wind directions were not generally the same as the directions from which high-concentration aerosol events were observed in the submicron data. This fact alone might imply that a mask for the aerosol data based on wind direction could be applied at ENA that would retain the regionally representative data. Masking the data from the two most impacted wind directions at $\mathrm{C} 1$, west to northwest for the airport runway and southeast to south for the road, would result in the loss of 39\% of the aerosol data. However, high-number-concentration aerosol events were not always observed in direct correspondence with the wind direction of the known sources that were discussed here. Examples of such events were found to occur during both seasons at C1 and S1. For this reason, masking AOS data based on wind direction alone, while straightforward and easy to apply, would not be the most precise method to isolate the influence of local aerosol at ENA.

Based on the analysis presented here, we determined that masking data points by wind direction or metadata was not the best method to remove local aerosol sources at ENA. Application of this method to ENA data would remove time periods without high aerosol concentrations as well as miss others from directions not associated with the known sources. However, creating a mask for local aerosol sources based on wind direction may be more suitable for application at other locations with less complex aerosol sources and meteorology - that is, close proximity and stable winds. Examples of potential application include more remote sites with minimal sources, such as those that might be encountered during ship-based deployments with smoke stacks, and/or ground-based deployments with onsite power generators.

A mathematical algorithm was developed based on previous aerosol analysis and optimized to mask high-concentration aerosol events at ENA using AOS data, specifically, using $N_{\text {tot }}$ from the CPC. The duration of the events must be oversampled in time and the rate of change in the data must be significantly higher than the baseline measurements to apply the algorithm. The one-minute CPC data at ENA shown here satisfied these requirements to create an aerosol mask. The ENA Aerosol Mask (ENAAM) was validated using $N_{\text {tot }}$ at two sites along with collocated observations and metadata. We also showed that median $N_{\text {tot }}$ were weakly affected by local aerosol events. Therefore, it may be possible to study longer-term trends in the aerosol data without masking the short-duration, high- $N_{\text {tot }}$ events at ENA. However, this technique would need to be further explored and does not resolve the issue for studying shorter-time-period aerosol variability as is required to study ambient aerosol processes.

While we maintain that the strategies for extracting regionally representative data depends on the specific need of the data user, the case study examined at ENA should be used to inform future efforts at ENA and other ARM locations with AOS data. We were able to provide and validate the identification of a regional baseline by comparing data from C1 and S1 under different aerosol regimes. Future work to better constrain the influence of local aerosol sources on ARM AOS data might focus on testing the application of different masking algorithms, including machine learning and artificial intelligence techniques. Other AOS measurements, such as the trace gas species, black carbon, and absorption data could be used to further validate the mask and/or in combination to create a higher-level aerosol mask. When available, AAF measurements should also be used to understand the vertical structure of aerosol within the region after masking the AOS data at ENA and at other locations within the ARM facility. 
Aerosol mask and validation techniques as we presented at ENA could be applied at other sites. High- $N_{\text {tot }}$ aerosol masks can be applied to other AOS data within the ARM facility and more generally at any continuous aerosol field campaign. After validation, the mask can be applied to the AOS data in general. Application of an aerosol mask can be done at any time after the data is collected and ingested into the ARM Data Center. Aerosol masks could be applied during routine measurements, IOPs, and/or selected data epochs. A value-added product (VAP) could be made available at ENA as well as at other locations and AMF deployments with AOS measurements whenever local aerosol sources are suspected to be present.

\subsection{Publications and Presentations}

The following journal article and presentations are the result of this work:

Gallo, F, J Uin, S Springston, J Wang, G Zheng, R Wood, EB Azevedo, A McComiskey, and AC Aiken. 2019. "Masking local aerosol using AOS data at an ARM facility in the Eastern North Atlantic: Comparison and validation with a supplementary aerosol site during ACE-ENA.” In preparation for Aerosol Chemistry and Physics.

Aiken, AC, F Gallo, J Uin, S Springston, C Kuang, A McComiskey, J Wang, G Zheng, C Flynn, and R Wood. 2019. "ENA AOS and Supplementary Site: Identifying and Filtering Local Aerosol Sources.” Presented at the ARM/ASR PI Meeting. Rockville, Maryland.

Gallo, F, J Uin, S Springston, R Wood, J Wang, A McComiskey, A Theisen, G Zheng, EB Azevedo, and AC Aiken. 2019. "Optimization of a post data-processing method to identify local aerosol events from continuous data collected by an Aerosol Observing System (AOS) and application to three years of data at Eastern North Atlantic (ENA).” To be presented at the American Geophysical Union Fall Meeting, San Francisco, California.

\subsection{References}

Brantley, HL, GSW Hagler, ES Kimbrough, RW Williams, S Mukerjee, and LM Neas. 2014. "Mobile air monitoring data-processing strategies and effects on spatial air pollution trends.” Atmospheric Measurement Techniques 7(7): 2169-2183, https://doi.org/10.5194/amt-7-2169-2014

Bullard, RL, J Uin, SR Springston, C Kuang, and S Smith. 2017. Aerosol Inlet Characterization Experiment Report. U.S. Department of Energy. DOE/SC-ARM-TR-191, https://www.arm.gov/publications/tech_reports/doe-sc-arm-tr-191.pdf

Burrows, SM, O Ogunru, AA Frossard, LM Russell, PJ Rasch, and SM Elliott. 2014. “A physically based framework for modeling the organic fractionation of sea spray aerosol from bubble film Langmuir equilibria.” Atmospheric Chemistry and Physics 14(24): 13601-13629, https://doi.org/10.5194/acp-14$\underline{13601-2014}$

Cai, Y, DC Montague, W Mooiweer-Bryan, and T Deshler. 2008. "Performance characteristics of the ultra high sensitivity aerosol spectrometer for particles between 55 and 800nm: Laboratory and field studies.” Journal of Aerosol Science 39(9): 759-769, https://doi.org/10.1016/j.jaerosci.2008.04.007 
Campagna, M, A Frattolillo, S Pili, G Marcias, N Angius, C Mastino, P Cocco, and G Buonanno. 2016. “Environmental Exposure to Ultrafine Particles inside and nearby a Military Airport.” Atmosphere 7(10): 138, https://doi.org/10.3390/atmos7100138

Dong, X, B Xi, A Kennedy, P Minnis, and R Wood. 2014. “A 19-month record of marine aerosol-cloudradiation properties derived from DOE ARM mobile facility deployment at the Azores. Part I: Cloud fraction and single-layered MBL cloud properties.” Journal of Climate 27(10): 3665-3682, https://doi.org/10.1175/JCLI-D-13-00553.1

Drewnick, F, T Böttger, SL von der Weiden-Reinmüller, SR Zorn, T Klimach, J Schneider, and S Borrmann. 2012. "Design of a mobile aerosol research laboratory and data processing tools for effective stationary and mobile field measurements.” Atmospheric Measurement Techniques 5(6): 1443-1457, https://doi.org/10.5194/amt-5-1443-2012

El Yazidi, A, M Ramonet, P Ciais, G Broquet, I Pison, A Abbaris, D Brunner, S Conil, M Delmotte, F Gheusi, F Guerin, L Hazan, N Kachroudi, G Kouvarakis, N Mihalopoulos, L Rivier, and D Serça. 2018. "Identification of spikes associated with local sources in continuous time series of atmospheric $\mathrm{CO}, \mathrm{CO}_{2}$ and $\mathrm{CH}_{4}$." Atmospheric Measurement Techniques 11(3): 1599-1614, https://doi.org/10.5194/amt-11$\underline{1599-2018}$

Feingold, G, and A McComiskey. 2016. "ARM's Aerosol-Cloud-Precipitation Research (Aerosol Indirect Effects).” Meteorological Monographs 57: 22.1-22.15, https://doi.org/10.1175/amsmonographs-d-150022.1

Hagler, GS, MY Lin, A Khlystov, RW Baldauf, V Isakov, J Faircloth, and LE Jackson. 2012. “Field investigation of roadside vegetative and structural barrier impact on near-road ultrafine particle concentrations under a variety of wind conditions.” Science of the Total Environment 419: 7-15, https://doi.org/10.1016/j.scitotenv.2011.12.002

Herndon, SC, TB Onasch, BP Frank, LC Marr, JT Jayne, MR Canagaratna, J Grygas, T Lanni, BE Anderson, D Worsnop, and RC Miake-Lye. 2005. "Particulate Emissions from in-use Commercial Aircraft.” Aerosol Science and Technology 39(8): 799-809, https://doi.org/10.1080/02786820500247363

Jimenez, JL, MR Canagaratna, NM Donahue, ASH Prevot, Q Zhang, JH Kroll, PF DeCarlo, JD Allan, H Coe, NL Ng, AC Aiken, KD Docherty, IM Ulbrich, AP Grieshop, AL Robinson, J Duplissy, JD Smith, KR Wilson, VR Lanz, C Hueglin, YL Sun, J Tian, A Laaksonen, T Raatikainen, J Rautiainen, P Vaattovaara, M Ehn, M Kulmala, JM Tomlinson, DR Collins, MJ Cubison, EJ Dunlea, JA Huffman, TB Onasch, MR Alfarra, PI Williams, K Bower, Y Kondo, J Schneider, F Drewnick, S Borrmann, S Weimer, K Demerjian, D Salcedo, L Cottrell, R Griffin, A Takami, T Miyosh, S Hatakeyama, A Shimono, YJ Sun, YM Zhang, K Dzepina, JR Kimmel, D Sueper, JT Jayne, SC Herndon, AM Trimborn, LR Williams, EC Wood, AM Middlebrook, CE Kolb, U Baltensperger, and DR Worsnop. 2009. "Evolution of organic aerosols in the atmosphere." Science 326(5959): 1525-1529, https://doi.org/10.1126/science.1180353

Kuang, C. 2016. Condensation Particle Counter (CPC) Instrument Handbook. U.S. Department of Energy. DOE/SC-ARM-TR-145, https://www.arm.gov/publications/tech_reports/handbooks/cpc_handbook.pdf 
Kyrouac, J. 2016. Aerosol Observing System Surface Meteorology (AOSMET) Instrument Handbook. U.S. Department of Energy. DOE/SC-ARM-TR-184, https://www.arm.gov/publications/tech_reports/handbooks/aosmet_handbook.pdf

Lighty, JS, JM Veranth, and AF Sarofim. 2000. "Combustion Aerosols: Factors Governing Their Size and Composition and Implications to Human Health.” Journal of the Air \& Waste Management Association 50(9): 1565-1618, https://doi.org/10.1080/10473289.2000.10464197

Logan, T, X Baike, and D Xiquan. 2014. “Aerosol properties and their influences on marine boundary layer cloud condensation nuclei at the ARM mobile facility over the Azores.” Journal of Geophysical Research - Atmospheres 119(8): 4859-4872, https://doi.org/10.1002/2013JD021288

Mather, JH, and JW Voyles. 2013. "The ARM Climate Research Facility: a Review of Structure and Capabilities”. Bulletin of the American Meteorological Society 94(3): 377-392, https://doi.org/10.1175/Bams-D-11-00218.1

McComiskey, A, and RA Ferrare. 2016. "Aerosol Physical and Optical Properties and Processes in the ARM Program.” Meteorological Monographs 57: 21.1-21.17, https://doi.org/10.1175/amsmonographs-d$\underline{15-0028.1}$

Mitchell, J, S Smith, L Gregory, T Madigan, A McMahon, SR Springston, and R Wagener. 2017. "Identifying the influence of local source emissions on the regional representativeness of AOS measurements using machine learning”. Presented at the ARM/ASR PI Meeting. Tysons, Virginia.

Moore, RH, MA Shook, LD Ziemba, JP DiGangi, EL Winstead, B Rauch, T Jurkat, KL Thornhill, EC Crosbie, C Robinson, TJ Shingler, and BE Anderson. 2017. “Take-off engine particle emission indices for in-service aircraft at Los Angeles International Airport.” Scientific Data 4: 170198-170198, https://doi.org/10.1038/sdata.2017.198

Quinn, PK, DB Collins, VH Grassian, KA Prather, and TS Bates.2015. "Chemistry and related properties of freshly emitted sea spray aerosol.” Chemical Reviews 115(10): 4383-4399, https://doi.org/10.1021/cr500713g

Remillard, J, P Kollias, E Luke, and R Wood. 2012. "Marine boundary layer cloud observations in the Azores.” Journal of Climate 25(21): 7381-7398, https://doi.org/10.1175/JCLI-D-11-00610.1

Shrivastava, M, MO Andreae, P Artaxo, HMJ Barbosa, LK Berg, J Brito, J Ching, RC Easter, J Fan, JD Fast, Z Feng, JD Fuentes, M Glasius, AH Goldstein, EG Alves, H Gomes, D Gu, A Guenther, SH Jathar, S Kim, Y Liu, S Lou, ST Martin, VF McNeill, A Medeiros, S de Sa, JE Shilling, SR Springston, RAF Souza, JA Thornton, G Isaacman-VanWertz, LD Yee, R Ynoue, RA Zaveri, A Zelenyuk, and C Zhao. 2019. "Urban pollution greatly enhances formation of natural aerosols over the Amazon rainforest.” Nature Communications 10: 1046, https://doi.org/10.1038/s41467-019-08909-4

Uin, J, AC Aiken, M Dubey, C Kuang, M Pekour, C Salwen, AJ Sedlacek, G Sennum, S Smith, J Wang, TB Watson, and S Springston. 2019. “Atmospheric Radiation Measurement (ARM) Aerosol Observing Systems (AOS) for surface-based in situ atmospheric aerosol and trace gas measurements.” Journal of Atmospheric and Oceanic Technology, in review. 
Uin, J. 2016. Ultra-High-Sensitivity Aerosol Spectrometer Instrument Handbook. U.S. Department of Energy. DOE/SC-ARM-TR-163, https://www.arm.gov/publications/tech_reports/handbooks/uhsas_handbook.pdf

Wang, J, R Wood, M Jensen, EB Azevedo, C Bretherton, D Chand, C Chiu, X Dong, J Fast, A Gettelman, S Ghan, S Giangrande, M Gilles, A Jefferson, P Kollias, C Kuang, A Laskin, E Lewis, X Liu, Y Liu, E Luke, A McComiskey, F Mei, M Miller, A Sedlacek, and R Shaw. 2019a. Aerosol and Cloud Experiments in Eastern North Atlantic (ACE-ENA) Field Campaign Report. U.S. Department of Energy. DOE/SC-ARM-19-012, https://www.arm.gov/publications/programdocs/doe-sc-arm-19-012.pdf

Wang, J. et al. 2019b. “Aerosol and Cloud Experiments in Eastern North Atlantic (ACE-ENA) Field Campaign.” Bulletin of the American Meteorological Society, in preparation.

Wood, R, M Wyant, CS Bretherton, J Rémillard, P Kollias, J Fletcher, J Stemmler, S de Szoeke, S Yuter, M Mille., D Mechem, G Tselioudis, JC Chiu, JAL Mann, EJ O’Connor, RJ Hogan, X Dong, M Miller, V Ghate, A Jefferson, Q Min P Minnis, R Palinkonda, B Albrecht, E Luke, C Hannay, and Y Lin. 2015. "Clouds, aerosol, and precipitation in the marine boundary layer: An ARM mobile facility deployment." Bulletin of the American Meteorological Society 96(3): 419-440, https://doi.org/10.1175/BAMS-D-13$\underline{00180.1}$

Wood, R. 2016. Clouds, Aerosol, and Precipitation in the Marine Boundary Layer (CAP-MBL) Final Campaign Report. U.S. Department of Energy. DOE/SC-ARM-14-039, https://www.arm.gov/publications/programdocs/doe-sc-arm-14-039.pdf

Zheng, G, Y Wang, AC Aiken, F Gallo, MP Jensen, P Kollias, C Kuang, E Luke, S Springston, J Uin, R Wood, and J Wang. 2018. "Marine boundary layer aerosol in the eastern North Atlantic: seasonal variations and key controlling processes.” Atmospheric Chemistry and Physics 18(23): 17615-17635, https://doi.org/10.5194/acp-18-17615-2018

Zheng, G, AJ Sedlacek, AC Aiken, Y Feng, TB Watson, S Raveh-Rubin, J Uin, ER Lewis, and J Wang. 2019. "Long-range transported North American wildfire aerosols observed in marine boundary layer of eastern North Atlantic.” Environmental International, in review.

Zhou, S, S Collier, J Xu, F Mei, J Wang, Y-N Lee, AJ Sedlacek, SR Springston, Y Sun, and Q Zhang. 2016. "Influences of upwind emission sources and atmospheric processing on aerosol chemistry and properties at a rural location in the Northeastern U.S.” Journal of Geophysical Research - Atmospheres 121(10): 6049-6065, https://doi.org/10.1002/2015JD024568 


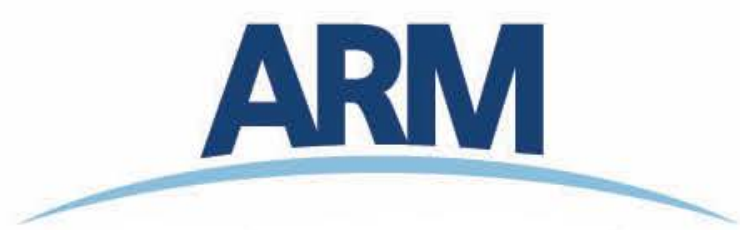

www.arm.gov
U.S. DEPARTMENT OF EN

Office of Science 